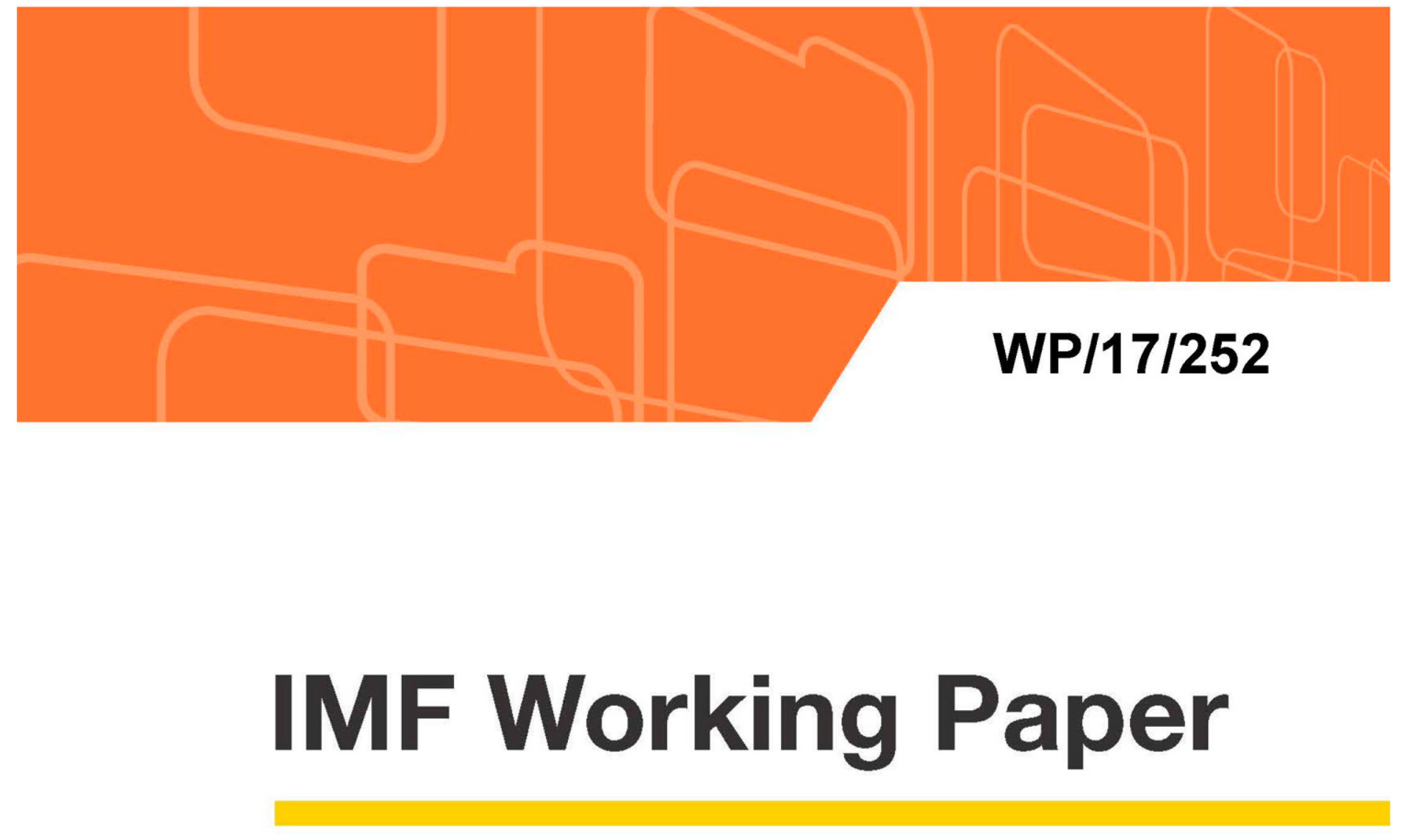

\title{
Bank Capital and Lending: An Extended Framework and Evidence of Nonlinearity
}

by Mario Catalán, Alexander W. Hoffmaister and Cicilia Anggadewi Harun

IMF Working Papers describe research in progress by the author(s) and are published to elicit comments and to encourage debate. The views expressed in IMF Working Papers are those of the author(s) and do not necessarily represent the views of the IMF, its Executive Board, or IMF management. 


\section{WP/17/252}

\section{IMF Working Paper}

\section{Bank Capital and Lending: An Extended Framework and Evidence of Nonlinearity}

by Mario Catalán, Alexander W. Hoffmaister and Cicilia Anggadewi Harun

IMF Working Papers describe research in progress by the author(s) and are published to elicit comments and to encourage debate. The views expressed in IMF Working Papers are those of the author(s) and do not necessarily represent the views of the IMF, its Executive Board, or IMF management. 


\title{
IMF Working Paper
}

Monetary and Capital Markets Department

\section{Bank Capital and Lending: An Extended Framework}

and Evidence of Nonlinearity

\section{Prepared by Mario Catalán, Alexander W. Hoffmaister and Cicilia Anggadewi Harun*}

Authorized for distribution by Udaibir S. Das

September 2017

IMF Working Papers describe research in progress by the author(s) and are published to elicit comments and to encourage debate. The views expressed in IMF Working Papers are those of the author(s) and do not necessarily represent the views of the IMF, its Executive Board, or IMF management.

\begin{abstract}
This paper studies the transmission of bank capital shocks to loan supply in Indonesia. A series of theoretically founded dynamic panel data models are estimated and find nonlinear effects of capital on loan growth: the response of weaker banks to changes in their capital positions is larger than that of stronger banks. This non-linearity implies that not only the level of capital but also its distribution across banks in the financial system affects the transmission of shocks to aggregate lending. Likewise, the effects of bank recapitalization on loan growth depend on banks' starting capital positions and the size of capital injections.
\end{abstract}

JEL Classification Numbers: G01, G21, G28, E32, E44, E51.

Keywords: Bank capital; Bank lending; Financial shocks; Transmission mechanisms.

Author's E-Mail Address: mcatalan@imf.org (corresponding); alexhoffmaister@gmail.com, and charun@bi.go.id.

*The authors would like to thank Tobias Adrian, Leonardo Martinez, Luis Brandao-Marques, Adolfo Barajas, Fabian Lipinsky, TengTeng Xu, and Federico Grinberg for useful comments and suggestions. The authors declare that they have no relevant or material financial interests that relate to the research described in this paper. The views expressed in this paper are those of the authors and should not be attributed to Bank Indonesia or the International Monetary Fund, its Executive Board, and its management. 


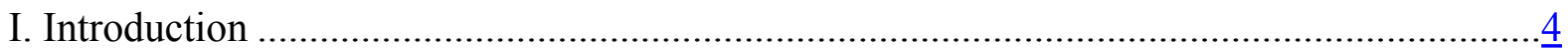

II. Theoretical Model …………………………………................................................

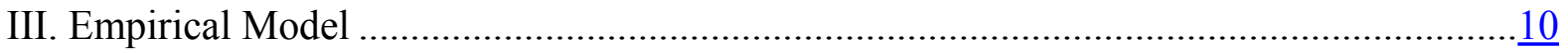

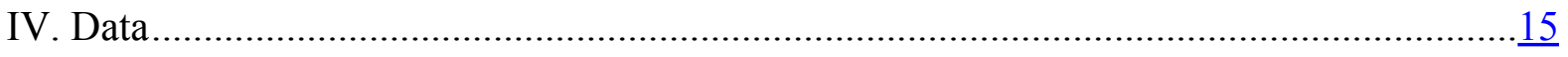

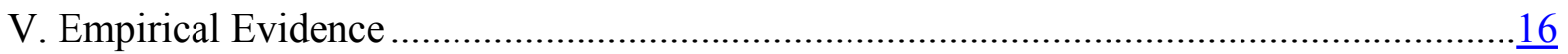

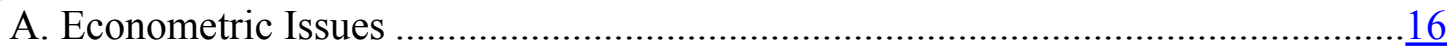

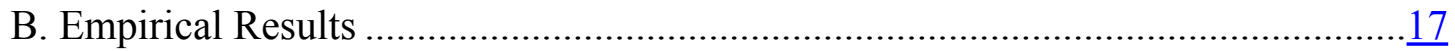

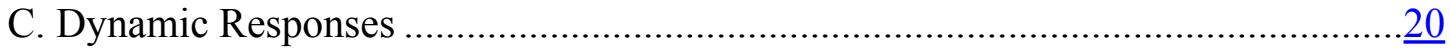

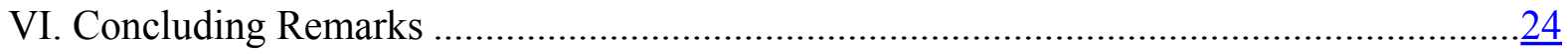

Tables

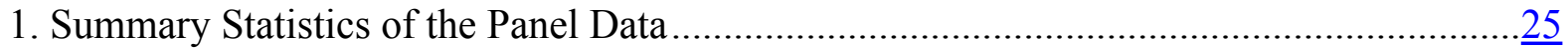

2. Pairwise Regressions of Loan Growth and ...................................................................

3. Response of Loan Growth to Changes in Bank-specific Fundamentals and Macroeconomic Variables: Basic Model with Constant Long-Run Growth (Eq. 6) ……………………...27

4. Response of Loan Growth to Changes in Bank-specific Fundamentals and Macroeconomic Variables: Extended Model with Long-Run Growth Determined only by Macroeconomic Variables

5. Response of Loan Growth to Changes in Bank-Specific Fundamentals and Macroeconomic Variables: Extended Model with Long-Run Growth Determined by Macroeconomic Variables and Levels of Bank-specific Fundamentals .

Figures

1. Cumulative Responses of Loan Growth and Capital Ratio Distances to a +1 Percentage Point Shock to Capital Ratios at Different Time Horizons, for Banks with Different Initial Capital Ratio Distances

2. Pairwise Relationships between Real Loan Growth and Changes in Capital

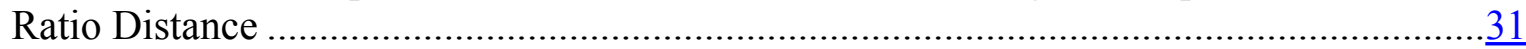

3. Impulse Responses of Loan Growth: Shocks to Capital Ratio Distance ..............................

4. Cumulative Responses of Loan Growth to $+/-1,5$ and 10 Percentage Point Shocks to Capital Ratios, for a Bank with Average Capital Ratio Distance .......................................

5. Cumulative Response of Aggregate Loan Growth for $+/-1$ Percentage Point Shocks to the Capital Ratio Distance.

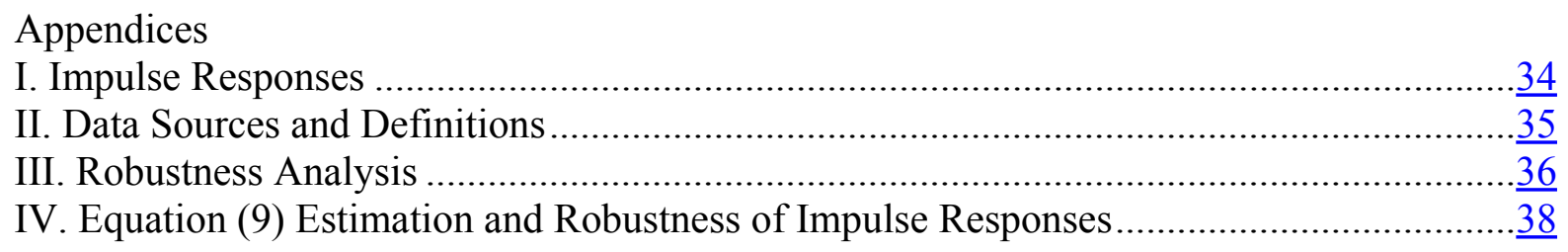

References 


\section{INTRODUCTION}

Understanding how bank lending responds to macroeconomic and financial shocks is crucial for central banks and other macro-prudential policy institutions. Part of the interest in this topic arises from the recognition that banks' lending decisions play a central role in the transmission of monetary policy (Gambacorta and Shin, 2016; Peek and Rosengren, 2015; and references therein). But its relevance extends to financial stability analysis.

To avoid underestimating capital losses and systemic risk, macroprudential analysis and stress tests must capture banks' behavioral responses to capital shocks and account for key macro-financial feedback loops (Hanson, Kashyap and Stein, 2011). ${ }^{1}$ In addition, once a systemic crisis materializes, it is important to know how effective bank capital injections are in restarting credit and economic growth (Laeven and Valencia, 2013a).

This paper addresses empirically the question of whether, and if so to what extent, banks adjust their lending in response to shocks in their capital positions. To this effect, this study develops a theoretically founded framework to model bank lending behavior and underpin the empirical evidence.

This study thus relates to the literature on the bank capital-lending nexus that sprang up in the early 1990s and continued expanding in the wake of the global financial crisis (Gambacorta and Shin, 2016; Berrospide and Edge, 2010; Adrian and Shin, 2010; and Gambacorta and Mistrulli, 2004). This paper also sheds light on the bank lending responses that are central to theories of adverse macro-financial feedback loops (Fahri and Tirole, 2016; Brunnermeier et al., 2016; Bocola, 2016; and Brunnermeier and Sannikov, 2016). This literature suggests that well-capitalized banks, or those with access to new sources of capital, can accommodate adverse capital shocks without cutting back their assets and loans. In contrast, capitalconstrained banks are more likely to "deleverage." In either case, bank lending responses to capital shocks need to be assessed empirically.

In this study, the empirical evidence stems from a unique dataset of granular supervisory data for the 118 banks comprising the Indonesian banking system during 2001-15. ${ }^{2}$ Two distinctive features of this dataset help refine estimates of the bank capital-lending nexus: it includes bank- and time-specific data for minimum capital requirements and lending interest rates. Following Gambacorta and Mistrulli (2004), this study defines bank capitalization as

\footnotetext{
${ }^{1}$ They characterize the macroprudential approach to financial regulation as "an effort to control the social costs associated with excessive balance-sheet shrinkage on the part of multiple financial institutions hit with a common shock." Stress tests can only serve as a tool to inform macroprudential regulatory decisions if they properly quantify banks' lending responses and their subsequent macro-financial feedback effects.

${ }^{2}$ So far, the empirical literature on the bank capital-lending nexus has focused (almost) exclusively on advanced economies. The lack of evidence for emerging economies is significant given the role played by aggregate bank lending in fueling boom-bust cycles in emerging economies; Schneider and Tornell (2004) provide a theoretical model motivated by the stylized facts documented in Kaminsky and Reinhart (1999). Also, over the last 50 years, banking crises have been more prevalent and costly in emerging economies than in advanced economies (Laeven and Valencia, 2013b).
} 
the amount of capital that a bank holds in excess of its minimum regulatory requirements ("capital ratio distance" or $C A R D$ ). In contrast with previous studies, the dataset details the minimum capital requirements prevailing for each bank over time. These data thus capture the complexities and shifts in regulatory regimes during the sample period. ${ }^{3}$ This specificity overcomes the main drawback of traditional capitalization measures: their inability to accurately discriminate between banks subject to varying regulatory constraints over time. In addition, bank- and time-specific lending interest rate data shed light on banks' market power and help disentangle demand and supply side determinants of lending.

The main contributions of this paper are as follows. First, it improves the estimation of the bank capital-lending nexus using a theoretical framework wherein banks operate in a market characterized by product (loan) differentiation and imperfect (monopolistic) competition. The departure from a perfectly competitive model is motived by the observed differentiation of lending interest rates across banks and their variation over time. Bank's profit maximization yields a mark-up equation that equates marginal revenue to the marginal cost of lending. This equation characterizes bank lending decisions and, together with a loan demand equation, determines market outcomes for loans and lending interest rates. The empirical analysis focuses on the panel estimation of the mark-up equation and its use to evaluate the dynamic response of loan growth to capital shocks.

Second, the empirical model differs from those used in previous studies. Bank lending depends on pre-determined bank-specific fundamentals (capital, liquidity, and nonperforming loan ratios), macroeconomic variables, and the lending interest rate. ${ }^{4}$ The latter is endogenous due to market power and thus instrumental variable techniques are used. Two (outside) instruments are employed: Tobin's Q for nonfinancial corporate borrowers of individual banks measures "investment opportunities" driving loan demand from firms (as in Hubbard, 1998; Fazzari, Hubbard, and Petersen, 1988; and references therein); and changes in housing prices capture wealth effects that influence household consumption and hence loan demand. Their validity is confirmed by standard statistical tests.

The empirical model separates the determinants of bank lending that affect the long-run growth path from those that only influence the transitional dynamics around this path. This is

\footnotetext{
${ }^{3}$ Under current regulation, banks are subject to the following minimum capital-to-risk weighted assets requirements: common equity tier 1 capital (CET1) (4.5 percent), total capital ( 8 percent). In addition, all banks must hold capital to cover a capital conservation buffer that is defined in terms of CET1 and being phased in over time (1.25 percent in 2017), and Pillar II add-ons ranging from 1 to 3 percentage points that are expressed in terms of total capital. Finally, four categories of domestic systemically important banks will be subject to capital surcharges (equivalent to $1,1.5,2$, and 2.5 percent of CET1 capital) starting in 2019. The capital requirement measure used in this paper incorporates not only the common minimum total capital-to-risk weighted assets ratio of 8 percent, but also the bank-specific Pillar II add-on determined by the supervisory authorities within the permissible range of variation.

${ }^{4}$ Non-performing loan ratios embed information about future credit losses and profitability which is not fully and simultaneously reflected in bank capital ratios. Following a sudden spike in the non-performing loan ratio, provisions are phased in according to a pre-determined schedule and over time gradually impact credit losses and capital. Also, liquidity is relevant for bank lending behavior because it implies less overall opacity on the asset side, which increases the capacity of the bank to raise funds.
} 
done using augmented autoregressive distributed lag (ARDL) models, which were proposed in a panel data context by Pesaran and Smith (1995) and Pesaran (2006) and employed in the economic growth literature by Bond, Leblebicioglu, and Schiantarelli (2010). Here, several empirical specifications are explored that progressively relax restrictions on long-run loan growth. ${ }^{5}$ This paper shows how bank lending responses change across long-run loan growth specifications.

Third, the empirical model allows for the presence of nonlinear effects of bank capital on loan growth associated with threshold effects - these arise when the marginal cost of lending increases at increasing rates as bank capitalization approaches minimum requirements. This paper provides strong evidence that such effects are important. Impulse responses, reflecting the mark-up equation and the dynamic evolution of $C A R D$ associated with the impact of loan growth on risk-weighted assets, bear out the hypothesis that bank lending becomes more sensitive to capital shocks as initial $C A R D$ declines. Figure 1 (top) summarizes this relationship: banks' lending responses to capital shocks depend on the initial CARD, with responses of weaker banks far exceeding those of stronger banks. ${ }^{6}$ For instance, after 16 quarters the cumulative lending response of a bank with $C A R D=-5$ percent is about $35(=1.64 / 1.21)$ percent larger than that of a bank with $C A R D=15$ percent. Note that the strength of the nonlinear effects is captured by the slopes of the curves. ${ }^{7}$

Beyond these empirical results, however, the evidence points to diminishing marginal effects whereby incremental additions of bank capital have positive but declining marginal effects on lending. Thus, the impact of bank recapitalizations on loan growth will depend on the size of the capital injections as well as on the banking system's initial capital position. ${ }^{8}$

Finally, "nonlinearity" implies that heterogeneity in bank capital buffers across banks matters for the transmission of shocks to aggregate lending. This study finds evidence that bank capital heterogeneity can be a substantial source of amplification at the aggregate level. Specifically, aggregate loan growth impulse responses to capital shocks using the historical data are consistently larger than those from a hypothetical banking system where all banks have the same $C A R D$. This suggests that a more homogeneous distribution of a given

\footnotetext{
${ }^{5}$ The empirical models in this study contrast with those used in previous studies, where bank-specific fundamentals affect loan growth and appear in the regressions in levels. Here, the most general empirical model includes the levels and changes (first differences) of bank-specific fundamentals, allowing these to affect both the long-run loan growth path and the transitional dynamics around this path. In these models, long-run loan growth is time-varying and reflects bank-specific and common (macro) factors. This study also explores the impact on the lending responses of more restrictive long-run loan growth specifications. Namely, the most restrictive specifications constrain long-run loan growth to be time-invariant and common across banks, or explained by unobserved bank characteristics (fixed effects); in these cases, bank-specific fundamentals enter only in changes (not in levels) and affect only the transitional dynamics.

${ }^{6}$ In nonlinear systems, impulse responses are history-specific, shock-specific, and asymmetric: responses thus vary depending on the size and sign of the shock (Koop, Pesaran, and Potter, 1996).

${ }^{7}$ If the model were linear, the cumulative lending responses would not depend on $C A R D$ and would be horizontal lines in Figure 1.

${ }^{8}$ The empirical findings presented in this paper suggest that capital injections targeted at weaker banks would be more effective in boosting loan growth than those aimed at stronger banks. However, from a broader perspective of systemic risk, it can be argued that-in the presence of confidence effects and interbank coordination problems - the stronger, not the weaker banks, should be bolstered (Choi, 2014).
} 
amount of capital across banks increases the resilience of aggregate lending to adverse capital shocks.

The rest of the paper is organized as follows. Sections II and III describe the theoretical and empirical models, respectively. Section IV describes the data. Section V presents the empirical evidence for Indonesia. Section VI concludes.

\section{THEORETICAL MODEL}

The banking industry is populated by a large number of competitive banks that raise deposits and offer differentiated credit products. Product differentiation implies that banks exert pricing power and a monopolistically competitive setting prevails in the loan market. Bank depositors exert market discipline, and the cost of deposit funding for a bank includes two components: a market-wide benchmark policy rate and a credit spread that varies with bankspecific fundamentals and macroeconomic variables. ${ }^{9}$

The underlying economy exhibits trend-growth, which implies that in the absence of shocks, the size of the banking system would grow at the same rate as the economy. In what follows, the model of the banking sector is presented in stationary form; when necessary, we refer to un-detrended variables, labeling them with the symbol “^”,

\section{Profits}

The profits of bank $i$ in period $t$ are given by $\Pi_{i, t}=r_{i, t}^{l} \cdot L_{i, t}-C\left(D_{i, t}, L_{i, t}, r_{t}^{d}, \boldsymbol{x}_{i, t-1}, \boldsymbol{z}_{t-1}\right)$, where $r_{i, t}^{l}$ denotes the bank's lending rate while $L_{i, t}$ and $D_{i, t}$ are respectively the amounts of loans and deposits. The function $C\left(\right.$.) represents the bank's funding and operational costs; $r_{t}^{d}$ is the policy rate; $\boldsymbol{x}_{i, t-1}$ is a vector of time-varying bank-specific fundamentals (CAMEL-type solvency and liquidity ratios that are measured at the end of period $t-1$ or equivalently at beginning of period $t$ ); and $\boldsymbol{z}_{t-1}$ is a vector of macroeconomic variables. All the variables (including the policy rate) are expressed in real terms.

\section{Loan Demand}

The (un-detrended) demand for loans of bank $i$ is given by: $\hat{L}_{i, t}\left(r_{i, t}^{l}, r_{t}^{l}, \boldsymbol{F}_{i, t}\right)=a_{i} \cdot \exp ^{\xi t+\beta_{1} \cdot r_{i, t}^{l}+\beta_{2} \cdot r_{t}^{l}+\gamma \cdot F_{i, t}}$, where $\xi$ is the rate of trend growth, $r_{t}^{l}$ is the (average) lending rate prevailing in the market (that is, offered by other banks) and $\boldsymbol{F}_{i, t}$ is a vector of factors that shift the demand for loans around the trend. These factors play a key role as instruments in the estimation of the mark-up equation discussed below. The loan demand function is downward sloping $\left(\beta_{1}<0\right)$, and credit products offered by different banks are characterized by imperfect substitution $\left(\beta_{2}>0\right)$.

\footnotetext{
${ }^{9}$ For simplicity, the model does not differentiate between deposits and other forms of debt funding. "Deposit funding" must be interpreted as including all forms of debt liabilities such as deposits, bonds, money market instruments, etc.
} 
Note that $L_{i, t}=\hat{L}_{i, t} \cdot \exp ^{-\xi t}$ and let $l_{i, t}$ denote the logarithm of real credit: $l_{i, t}=\ln \hat{L}_{i, t}$. The log-detrended loan demand is linear in interest rates and the vector $\boldsymbol{F}_{i, t}:{ }^{10}$

$$
\ln L_{i, t}=\ln \hat{L}_{i, t}-\xi t=l_{i, t}-\xi t=\alpha_{i}+\beta_{1} \cdot r_{i, t}^{l}+\beta_{2} \cdot r_{t}^{l}+\gamma \cdot \boldsymbol{F}_{i, t} .
$$

\section{Costs}

The function $C($.) represents the bank's funding and operational costs, and is given by:

$$
C(.)=\left(r_{t}^{d}+\boldsymbol{\delta}_{0} \cdot \boldsymbol{x}_{i, t-1}+\boldsymbol{\delta}_{1} \cdot \boldsymbol{z}_{t-1}\right) \cdot D_{i, t}+\left(\delta_{2}+\boldsymbol{\delta}_{3} \cdot \boldsymbol{x}_{i, t-1}\right) \cdot L_{i, t}+\frac{\delta_{4}}{2} \cdot \sum_{s=1}^{p} \psi_{s} \cdot \frac{\left(L_{i, t}-L_{i, t-s}\right)^{2}}{L_{i, t-s}} .
$$

In equation (2) the first three terms represent the cost of funding. The bank pays a credit spread $\left(\boldsymbol{\delta}_{0} \cdot \boldsymbol{x}_{i, t-1}+\boldsymbol{\delta}_{1} \cdot \boldsymbol{z}_{t-1}\right)$ over the policy rate $r_{t}^{d}$, which is influenced by the disciplinary action of depositors $\left(\boldsymbol{\delta}_{0} \cdot \boldsymbol{x}_{i, t-1}\right)$-depositors demand higher interest rates from banks exhibiting weaker fundamentals - and macroeconomic conditions $\left(\boldsymbol{\delta}_{1} \cdot \boldsymbol{z}_{t-1}\right)$.

The fourth and fifth terms, $\left(\delta_{2}+\boldsymbol{\delta}_{3} \cdot \boldsymbol{x}_{i, t-1}\right) \cdot L_{i, t}$, include operational costs. Normal deposit and lending activities demand the use of resources such as labor and physical capital that cost $\left(\delta_{2} \cdot L_{i, t}\right)$. The bank also incurs costs that depend on the intensity of supervision to which it is subject, which in turn depend on the strength of the bank's fundamentals $\left(\boldsymbol{\delta}_{3} \cdot \boldsymbol{x}_{i, t-1}\right){ }^{11}$

The final term represents the costs of adjusting the supply of loans to levels that are above or below trend growth. In particular, the faster the desired deviation of the new stock of loans from its trend level, the larger the bank's adjustment costs. ${ }^{12}$

\section{Bank's Optimization Problem}

The bank maximizes profits $\Pi_{i, t}$ by choosing the amount of loans $L_{i, t}$, taking as given the loan demand function (1) and the cost function (2). Note that in this problem, bank-specific fundamentals $\boldsymbol{x}_{i, t-1}$ are pre-determined and thus unaffected by current lending decisions. The first order optimization condition, equating the bank's marginal revenue and marginal cost, is given by:

$$
r_{i, t}^{l}+L_{i, t} \cdot \frac{\partial r_{i, t}^{l}}{\partial L_{i, t}}=\left(r_{t}^{d}+\boldsymbol{\delta}_{0} \cdot \boldsymbol{x}_{i, t-1}+\boldsymbol{\delta}_{1} \cdot \boldsymbol{z}_{t-1}\right) \cdot \frac{\partial D_{i, t}}{\partial L_{i, t}}+\left(\delta_{2}+\boldsymbol{\delta}_{3} \cdot \boldsymbol{x}_{i, t-1}\right)+\delta_{4} \cdot \sum_{s=1}^{p} \psi_{s} \cdot\left(\frac{L_{i, t}-L_{i, t-s}}{L_{i, t-s}}\right) .
$$

\footnotetext{
${ }^{10}$ Other variables that refer to quantities $\left(\hat{D}_{i, t}\right.$ and $\hat{C}_{i, t}$ ) are detrended in the same manner, and the corresponding log transformations of these variables are expressed in lower case.

${ }^{11}$ Under risk-based supervision, banks with weaker fundamentals (poorer asset quality and lower capital or liquidity ratios) would have more frequent and invasive supervision. Supervisory activities consume time of senior managers and technical teams, and other resources that could be allocated to productive activities.

${ }^{12}$ The inclusion of adjustments costs is common in the literature and results in the inclusion of lagged dependent variable terms in the empirical mark-up equation.
} 
The bank's marginal revenue function is obtained from (1), and is given by $r_{i, t}^{l}+\frac{1}{\beta_{1}}$. Assume for simplicity that $\frac{\partial D_{i, t}}{\partial L_{i, t}}=\theta>1$ : the bank fully finances marginal loans with deposits (instead of equity) but it has a target ratio of liquid assets-to-deposits, and hence, the bank must raise more than one unit of deposits to increase the amount lent by one unit. And approximate the dynamic adjustment of the loan amount by $\left(\frac{L_{i, t}-L_{i, t-s}}{L_{i, t-s}}\right) \approx\left(\ln L_{i, t}-\ln L_{i, t-s}\right)$ to obtain the following mark-up equation:

$r_{i, t}^{l}+\frac{1}{\beta_{1}}=\theta \cdot\left(r_{t}^{d}+\boldsymbol{\delta}_{0} \cdot \boldsymbol{x}_{i, t-1}+\boldsymbol{\delta}_{1} \cdot \boldsymbol{z}_{t-1}\right)+\left(\delta_{2}+\boldsymbol{\delta}_{3} \cdot \boldsymbol{x}_{i, t-1}\right)+\delta_{4} \cdot\left(\sum_{s=1}^{p} \psi_{s}\right) \cdot \ln L_{i, t}-\delta_{4} \cdot \sum_{s=1}^{p} \psi_{s} \cdot \ln L_{i, t-s}$.

Re-arranging terms, the mark-up equation can be written as follows:

$$
\ln L_{i, t}=\rho_{0}+\rho_{1} \cdot r_{i, t}^{l}+\rho_{2} \cdot r_{t}^{d}+\boldsymbol{\rho}_{3} \cdot \boldsymbol{x}_{i, t-1}+\boldsymbol{\rho}_{4} \cdot \boldsymbol{z}_{t-1}+\sum_{s=1}^{p} \lambda_{s} \cdot \ln L_{i, t-s}
$$

where $\rho_{0}=\left(\frac{1}{\beta_{1}}-\delta_{2}\right) \cdot\left[\delta_{4} \cdot \sum_{s=1}^{p} \psi_{s}\right]^{-1} ; \rho_{1}=\left[\delta_{4} \cdot \sum_{s=1}^{p} \psi_{s}\right]^{-1} ; \rho_{2}=-\theta \cdot\left[\delta_{4} \cdot \sum_{s=1}^{p} \psi_{s}\right]^{-1} ;$

$\boldsymbol{\rho}_{3}=-\theta \cdot\left(\delta_{0}+\boldsymbol{\delta}_{3}\right) \cdot\left[\delta_{4} \cdot \sum_{s=1}^{p} \psi_{s}\right]^{-1} ; \boldsymbol{\rho}_{4}=-\theta \cdot \boldsymbol{\delta}_{1} \cdot\left[\delta_{4} \cdot \sum_{s=1}^{p} \psi_{s}\right]^{-1} ; \lambda_{s}=\psi_{s} \cdot\left[\sum_{s=1}^{p} \psi_{s}\right]^{-1}$.

The solution to the bank's optimization problem is given by the pair of values $\left(\ln L_{i, t}, r_{i, t}^{l}\right)$ that simultaneously satisfy the demand equation (1) and the mark-up equation (3).

By taking first (time) differences, the system of equations that solves the banks' optimization problem can be expressed as follows:

$$
\begin{gathered}
\Delta l_{i, t}=\xi+\beta_{1} \cdot \Delta r_{i, t}^{l}+\beta_{2} \cdot \Delta r_{t}^{l}+\gamma \cdot \Delta \boldsymbol{F}_{i, t} \\
\Delta l_{i, t}=\lambda_{0}+\xi+\rho_{1} \cdot \Delta r_{i, t}^{l}+\rho_{2} \cdot \Delta r_{t}^{d}+\rho_{3} \cdot \Delta \boldsymbol{x}_{i, t-1}+\rho_{4} \cdot \Delta \boldsymbol{z}_{t-1}+\sum_{s=1}^{p} \lambda_{s} \cdot \Delta l_{i, t-s} .
\end{gathered}
$$

In equation (5), $\lambda_{0}=-\xi \cdot \sum_{s=1}^{p} \lambda_{s}$, and $\Delta$ denotes time change (e.g. $\Delta \boldsymbol{x}_{i, t-1}=\boldsymbol{x}_{i, t-1}-\boldsymbol{x}_{i, t-2}$ ). Here loan growth is the sum of its long-run loan growth component $\left(\lambda_{0}+\xi\right)$ and the transitional dynamics around it. Note that the long-run loan growth rate- - which can also be written as $\xi \cdot\left(1-\sum_{s=1}^{p} \lambda_{s}\right)$-is time-invariant and common across banks. ${ }^{13}$

\footnotetext{
${ }^{13}$ The standard "order" identification condition for a two (simultaneous) equation system requires that the estimated equation exclude at least one exogenous variable (total number of endogenous variables minus one) associated with the other equation. As discussed below, the markup equation excludes housing price inflation and Tobin's Q that are associated with the loan demand curve (part of $\boldsymbol{F}_{i, t}$ ) so that the markup equation is overidentified.
} 


\section{Transmission Mechanism of Capital Shocks}

In this model, a positive shock to bank $i$ 's capital ratio (a component of the vector $\boldsymbol{x}$ ) would be transmitted to its lending (supply) through two channels. First, higher capitalization reduces the marginal cost of debt funding and lending (through $\boldsymbol{\delta}_{0} \cdot \boldsymbol{x}_{i, t-1}$ in equation (2)). ${ }^{14}$

Second, higher capitalization reduces marginal operational costs associated with the intensity of supervision (through $\boldsymbol{\delta}_{3} \cdot \boldsymbol{x}_{i, t-1}$ in equation (2)). Both effects prompt the bank to expand lending through debt creation.

The empirical model below allows for quadratic effects of bank capital distance on loan growth. This is because under risk-based supervision, supervisory intensity is likely to rise sharply for banks with deteriorating capital positions and increasing probability of becoming undercapitalized; also, debt holders could demand increasing rates of return to bear increasing levels of default risk. Thus, the marginal cost of lending could increase at an increasing rate as a bank's capitalization declines and approaches the minimum requirement, generating threshold effects. Whether this is indeed the case is an empirical question that is considered below.

\section{EMPIRICAL MODEL}

The objective of the empirical analysis is to estimate the mark-up equation and understand the dynamics of loan growth and CARD following a capital shock. In this regard, "basic" ARDL models are specified to closely resemble equation (5) where the long-run loan growth is time-invariant. "Extended" ARDL models consider time-varying specifications of long-run loan growth. Impulse response functions are computed to characterize loan growth and $C A R D$ dynamics following capital shocks. ${ }^{15}$

\section{A. Basic ARDL Model: Time-Invariant Long-run Loan Growth}

Consistent with mark-up equation (5), the empirical model distinguishes between factors that affect the long-run loan growth path and those that influence the transitional dynamics around this path. Specifically, for bank $i$ the following $\operatorname{ARDL}(p, p)$ model is specified:

$$
\Delta l_{i, t}=\xi+\sum_{s=1}^{p} \alpha_{s} \cdot \Delta l_{i, t-s}+\sum_{s=1}^{p} \boldsymbol{\beta}_{s} \cdot \Delta \boldsymbol{x}_{i, t-s}+\sum_{s=1}^{p} \boldsymbol{\gamma}_{s} \cdot \Delta \boldsymbol{z}_{i, t-s}+\sum_{s=0}^{p} \boldsymbol{\delta}_{s} \cdot \Delta \boldsymbol{i}_{i, t-s}+\mu_{i, t}
$$

\footnotetext{
${ }^{14}$ The link between bank capitalization and cost of debt funding is well established in the literature and underpins the "bank lending channel;" see, for instance, Gambacorta and Mistrulli (2003). When the market for bank debt is subject to frictions, a bank must pay a "lemon premium" to issue uninsured debt liabilities; higher capital ratios mitigate the lemon problem and thus reduce the cost of debt funding. Also, as banks are highly leveraged institutions, significant expansions of lending such as those typically observed during business cycles cannot be fully financed by changes in capital. Instead, higher capitalization allows banks to issue additional debt, which ends up funding most of the new lending. This mechanism is also consistent with the behavior of banks documented in Adrian and Shin (2010).

${ }^{15}$ The ARDL approach has the distinct advantage that it “... is robust to the unit-root properties of the underlying series and knowledge of the order of integration of the variables is not necessary. This allows one to test for the existance of a long-run relation without having to pretest a variable for a unit root..." (AssesnmachWesche and Pesaran, 2008, p. 6).
} 
where the long-run loan growth, $\xi$ is common across banks and time invariant. A second version of equation (6) assumes that long-run loan growth is time-invariant but bank-specific, whereby $\xi$ is replaced by fixed effects $d_{i}$ capturing unobservable characteristics of individual banks. Panel estimation is performed on equation (6), with the vector of time changes in bank-specific fundamentals defined as:

$$
\Delta \boldsymbol{x}_{i, t-s}=\left[\Delta N P L R_{i, t-s}, \Delta L A T A_{i, t-s}, \Delta C A R D_{i, t-s}, \Delta C A R D_{i, t-s}^{2}\right],
$$

where NPLR, LATA, and CARD denote respectively the bank's nonperforming loan rate, the ratio of liquid assets to total assets, and the difference between the risk-weighted capital adequacy ratio and the regulatory minimum. And the vector of time changes in macroeconomic variables (excluding the nominal policy rate) is given by

$$
\Delta \boldsymbol{z}_{t-s}=\left[\Delta R G D P G_{t-s}, \Delta I N F_{t-s}\right],
$$

where $R G D P G_{i, t-s}$ denotes real GDP growth and, hence, $\triangle R G D P G_{i, t-s}$ represents the acceleration of real GDP (the change in the rate of growth of real GDP); $\Delta I N F_{i, t-s}$ denotes the change in the rate of inflation. For its part, $\Delta \boldsymbol{i}_{i, t-s}$ represents a vector of time changes in the nominal interest rates:

$$
\Delta i_{i, t-s}=\left[\Delta i_{i, t-s}^{l}, \Delta i_{t-s}^{d}\right],
$$

where $i_{i, t-s}^{l}$ is the bank-specific nominal lending rate, and $i_{t-s}^{d}$ is the policy rate (common across banks). Both are defined as the sum of the corresponding real rates and the rate of inflation.

Note that the error term in equation (6), $\mu_{i, t}$, has been assumed to have zero mean and a block diagonal variance-covariance matrix, $\sigma^{2} \boldsymbol{I}_{T} \otimes \boldsymbol{I}_{N}$ where $\sigma^{2}$ denotes the variance of the error term, and $\boldsymbol{I}_{T}$ and $\boldsymbol{I}_{N}$ are identity matrices with dimensions equal to the total number of quarterly observations $(T)$ and the number of banks in the panel $(N)$.

\section{B. Extended ARDL Model: Time-varying Long-run Loan Growth}

The extended ARDL model allows long-run loan growth to vary over time and across banks. Specifically, the first version of the model allows the long-run growth path to be affected by (observable) macroeconomic conditions (in addition to the bank-specific fixed effects):

$$
\xi_{i, t}=d_{i}+\boldsymbol{\theta}_{1} \cdot \boldsymbol{z}_{t}+v_{i, t} .
$$

In equation (7), the coefficient vector $\boldsymbol{\theta}_{1}$ reflects the sensitivity of the long-run loan growth rate to changes in macroeconomic conditions $\boldsymbol{z}_{t}$. Note that equation (7) constrains the longrun loan growth rate's time variation to be common across banks. This feature is akin to including time effects in the model, but relying on (observable) $\boldsymbol{z}_{t}$ has the advantage of enabling the model to recover the impact of macroeconomic determinants on long-run loan growth. 
The second version of the extended model adds time-varying bank-specific factors $\boldsymbol{x}_{i, t-1}$ :

$$
\xi_{i, t}=d_{i}+\boldsymbol{\theta}_{1} \cdot \boldsymbol{z}_{t}+\boldsymbol{\theta}_{2} \cdot \boldsymbol{x}_{i, t-1}+v_{i, t},
$$

where coefficient vector $\boldsymbol{\theta}_{2}$ reflects the sensitivity of the long-run loan growth rate to changes in bank-specific factors. Equation (7') thus extends the time variation in long-run loan growth so that it now also differs across banks.

Panel estimation is performed on the empirical mark-up equations resulting from substituting equations (7) or (7') into equation (6):

$$
\begin{aligned}
\Delta l_{i, t} & =d_{i}+\boldsymbol{\theta}_{1} \cdot \boldsymbol{z}_{t}+\boldsymbol{\theta}_{2} \cdot \boldsymbol{x}_{i, t-1}+\sum_{s=1}^{p} \alpha_{s} \cdot \Delta l_{i, t-s}+\sum_{s=1}^{p} \boldsymbol{\beta}_{s} \cdot \Delta \boldsymbol{x}_{i, t-s}+\sum_{s=1}^{p} \gamma_{s} \cdot \Delta \boldsymbol{z}_{i, t-s} \\
& +\sum_{s=0}^{p} \boldsymbol{\delta}_{s} \cdot \Delta \boldsymbol{i}_{i, t-s}+\varepsilon_{i, t},
\end{aligned}
$$

where $\theta_{2}=0$ in the first version of the extended model. Note that the error term in equation (8) is implicitly defined as $\varepsilon_{i, t}=\mu_{i, t}+v_{i, t}$. This study does not seek to separately identify error terms $\mu_{i, t}$ and $v_{i, t}$; as in the basic ARDL model, equation (8) assumes that the (combined) error term $\varepsilon_{i, t}$ has a zero mean and is homoscedastic and uncorrelated over time and across banks.

\section{Impulse Responses following Capital Shocks}

In general, impulse response functions for shocks to right-hand side variables in ARDL models can be computed as the difference between a counterfactual and a baseline dynamic forecast (Hamilton, 1994, p. 318-9). The ARDL models discussed below exhibit nonlinearity as they include both a linear and a quadratic term for $\triangle C A R D$. This feature implies that impulse response functions for capital shocks will depend on $C A R D_{i, 0}$ and the history up to time $t=0$ (see Appendix I for details). Impulse responses are thus "bank-specific," "historyspecific," "shock-specific," and "assymetric"-properties shared by more general classes of nonlinear models (Koop, Pesaran, and Potter, 1996). In this study, it follows that a common capital shock applied to all banks will result in 118 bank-specific impulse responses, each of these depending on the specific quarter when the shock hits and on the size and sign of the shock.

Computing impulse responses from single equation ARDL models, however, would be subject to an important limitation: a (shocked) right-hand side variable would lack endogenously generated dynamics. ${ }^{16}$ This is particularly constraining for the purpose of assessing the response of $\Delta l$ to $\triangle C A R D$ shocks because loan growth affects risk-weighted assets, which serve as the denominator of $C A R D$. Impulse responses based only on the markup equation would hold $C A R D$ constant following an initial shock and would not be informative of how capital shocks affect lending in the real world. This is because these responses would unrealistically assume that banks adjust their capital positions through profit

\footnotetext{
${ }^{16}$ This contrasts with multiple equation models, including VAR models, where all variables have endogenous dynamics.
} 
retention or capital injections to ensure that the ratio of capital to risk-weighted assets remains unchanged.

\section{An Equation for CARD}

To overcome this limitation, this study introduces an equation that endogenizes the evolution of $C A R D$ by capturing the impact of loan growth on $C A R D$ through its effect on riskweighted assets. Specifically, consider writing the capital ratio distance as $C A R D_{i, t}=C A R_{i, t}-\overline{C A R}_{i, t}=\frac{K_{i, t}}{R W A_{i, t}}-\overline{C A R}_{i, t}$, where $K_{i, t}$ and $\overline{C A R}_{i, t}$ denote, respectively, the amount of capital and the minimum capital requirement ratio; and risk weighted assets are defined as the product of the average risk weight $(\Theta)$ and the amount of loans, $R W A_{i, t}=\Theta \cdot L_{i, t}$. The first (time) differences in $C A R D$ and $K$ can be expressed as $\Delta C A R D_{i, t}=\frac{K_{i, t}}{\Theta \cdot L_{i, t}}-\frac{K_{i, t-1}}{\Theta \cdot L_{i, t-1}}-\Delta \overline{C A R}_{i, t}$ and $\Delta K_{i, t}=R O A_{i, t} \cdot\left(\frac{\mathrm{A}_{i, t-1}}{L_{i, t-1}}\right) \cdot \operatorname{ret}_{i, t} \cdot L_{i, t-1}+C I_{i, t}$, where ret is the retention ratio, that is, the fraction of profits not distributed as dividends, $R O A$ denotes return on assets, and $C I$ denotes external capital injections. Thus, the equation tracking the dynamics of the capital ratio can be expressed as:

$\Delta C A R D_{i, t} \approx R O A_{i, t} \cdot\left(\frac{\mathrm{A}_{i, t-1}}{L_{i, t-1}}\right) \cdot\left(\frac{r e t_{i, t}}{\Theta}\right)-C A R_{i, t-1} \cdot \Delta \ln L_{i, t}+\frac{C I_{i, t}}{R W A_{i, t-1}}-\Delta \overline{C A R}_{i, t}$, where the first

right-hand side term reflects the impact of retained profits on changes in $C A R D$, and subsequent terms reflect respectively the drag imposed by loan growth, the impact of externally-generated capital injections, and the effect of changes in the minimum capital requirement ratio.

\section{Capital Shocks}

Let $\Xi_{i}^{\text {AVG }}$ denote the "average" historical level of bank $i$ 's retained profits and define $\Xi_{i, t}$ as the deviation from this average at time $t$. Changes in CARD can now be written as:

$$
\triangle C A R D_{i, t} \approx \Xi_{i}^{\mathrm{AVG}}-C A R_{i, t-1} \cdot \Delta \ln L_{i, t}+\omega_{i, t}^{C A R D},
$$

where $\omega_{i, t}^{C A R D}=\Xi_{i, t}+\frac{C I_{i, t}}{R W A_{i, t-1}}-\Delta \overline{C A R}_{i, t}$.

In equation (9), $\omega_{i, t}^{C A R D}$ thus comprises "capital shocks" $\left(\Xi_{i, t}+\frac{C I_{i, t}}{R W A_{i, t-1}}\right)$ and "capital

requirement shocks" $\left(\triangle \overline{C A R}_{i, t}\right)$. The former includes changes in the numerator of the capital ratio driven by above-or-below average retention of profits $\left(\Xi_{i, t}\right)$ or external capital 
injections $\left(\frac{C I_{i, t}}{R W A_{i, t-1}}\right)$. In what follows, for simplicity, we refer to $\omega_{i, t}^{C A R D}$ as "capital shocks" but these can also be interpreted as "capital requirement shocks" of opposite sign. ${ }^{17,18}$

\section{The Two-Equation Structural Model}

The mark-up equations (6) or (8) and equation (9) can be thought to be two "structural" equations of a larger dynamic model in the sense that their shocks $\left(\omega_{i, t}^{\text {CARD }}\right.$ and $\left.\varepsilon_{i, t}\right)$ are contemporaneously uncorrelated. ${ }^{19}$ Structural shocks in dynamic models, such as VAR models, are often identified using timing assumptions to define a recursive system (devoid of simultaneity). ${ }^{20}$ Note that simultaneity is absent in mark-up equations (6) or (8) and equation (9): structural shocks to loan "supply" $\left(\varepsilon_{i, t}\right)$ have contemporaneous effects on $\triangle C A R D_{i, t}$, but structural shocks to capital $\left(\omega_{i, t}^{C A R D}\right)$ have no contemporaneous impact on $\Delta l_{i, t} \cdot{ }^{21} \mathrm{~A}$ structural capital shock can thus be identified and its effects simulated using impulse response functions. More specifically, impulse responses presented in this paper are based on dynamic forecasts for a two-equation (nonlinear) system, namely equations (6) or (8) and (9), and capture the effects of a capital shock at time $t=0\left(\omega_{i, 0}^{\text {CARD }}\right)$, with bank $i$ 's loans and riskweighted assets (the denominator of the capital ratio) remaining unchanged at time $t=0$ $\left(\varepsilon_{i, 0}=0\right){ }^{22}$ Thus, the change in $C A R D_{0}$ triggered by the capital shock must be interpreted as a shock to the numerator of the capital ratio.

\footnotetext{
${ }^{17}$ In principle, a hypothetical positive capital requirement shock that is fully matched by an equivalent capital injection in the same quarter will not trigger a dynamic lending response; but banks do not target $C A R D$ levels in this way. In fact, changes in regulatory requirements are of marginal significant in explaining movements in bank capital ratios: fixed-effects regression of $\triangle C A R$ on $\triangle \overline{C A R}$ has an $\mathrm{R}^{2}=0.01$.

${ }^{18}$ To the extent changes in capital requirements are phased-in and thus pre-announced, shocks in " $\overline{C A R}$ " could have a different inpact on lending than other capital shocks. But this does not seem to be the case here: the empirical evidence is unchanged qualitatively when "shocks" in $\overline{C A R}$ are set to zero. Specifically, replacing the actual $C A R D$ with $C A R$ minus the average capital requirement (8 percent) one obtains a hypothetical $C A R D$ reflecting no changes in capital requirements. Using this hypothetical $C A R D$ to estimate the preferred model results in coefficients and impulse responses that are very similar to those reported in Table 5 and depicted in Figure 3. Quantitatively, the accumulated lending responses based on analysis with the hypothetical $C A R D$ are slightly larger at a horizon of 4 quarters $(0.01=.2565-.2469)$, and slightly lower at horizons 8,12 , and 16 quarters (respectively, $-0.1=0.7289-0.7388,-0.02=1.0730-1.0946$, and $-0.02=1.2371-1.2660$ ).

${ }^{19}$ A full dynamic model would also include equations for all other variables in $\boldsymbol{x}$ and $\boldsymbol{z}$. Such model, however, would not be a standard VAR model due to the nonlinearities in equations (6) or (8) and in equation (9).

${ }^{20}$ Identifying "structural" shocks of all the variables included in $\boldsymbol{x}$ and $\boldsymbol{z}$ would entail the estimation of a larger system of equations that lies beyond the scope of this study.

${ }^{21}$ In VAR jargon, loan "supply" shocks are first in the recursive ordering.

${ }^{22}$ Note that equation (9) introduces an new source of nonlinearity: the interaction term $C A R_{i, t-1}$ multiplied by $\Delta \ln L_{i, t}$. Note further that computing the dynamic forecasts requires adding identities to tie changes to levels of the relevant variables as well as to tie $C A R D$ to its square.
} 


\section{DATA}

The unique panel data comprises supervisory bank-by-bank information for 118 banks operating in Indonesia at the end of 2014, and the (unbalanced) sample covers 56 quarters, starting with the first quarter of 2001. The bank-specific data as well as macroeconomic data were obtained from Bank Indonesia. Data sources and definitions are detailed in Appendix II. Table 1 reports summary statistics for variables used in the panel data analysis.

Figure 2 depicts a pairwise relationship between bank loan growth $(\Delta l)$ and changes in bank-specific capital ratio distance $(\triangle C A R D)$. The left panel shows a scatterplot for data across banks, that is, the data correspond to 118 bank observations obtained by averaging each bank's data over 55 quarters. The right panel shows a scatterplot for data in the time dimension, that is, 55 quarterly observations obtained by averaging the data in each quarter over the 118 banks. These scatterplots reveal weak and negative correlation between $\Delta l$ and $\triangle C A R D$ across banks and in the time dimension, which suggests that banks actively manage their balance sheets by adjusting their loans pro-cyclically to changes in risk-weighted capital ratios. Although based on a risk-weighted capitalization measure, this finding is consistent with the null (positive) relation between leverage and asset growth found for commercial banks (securities brokers and dealers) in the United States by Adrian and Shin (2010).

These relationships are no more than a first pass of the data and in terms of the discussion on the mark-up equation above, they can only suggest (imperfectly) the existence of effects related to the transitional dynamics (but not those related to long-run growth).

Table 2 explores potential nonlinearities in the pairwise relationships between loan growth and changes in bank-specific capital ratio (distance). The top panel shows linear regressions of $\triangle l$ on $\triangle C A R D$ (equations corresponding to the straight lines in Figure 2) with the columns grouping the results based on data across banks and along the time dimension. The bottom panel shows regressions of "adjusted" loan growth on squared changes in bankspecific capital ratio (distance).

"Adjusted" loan growth subtracts from loan growth the part that is explained by the linear term associated with changes in capital ratio (distance). Specifically, starting from the regression $\Delta l=\beta_{0}+\beta_{1} \cdot \triangle C A R D+\beta_{2} \cdot \triangle C A R D^{2}+\varepsilon$, adjusted loan growth is defined as $\Delta l-\beta_{0}-\beta_{1} \cdot \triangle C A R D$. The $\mathrm{R}^{2}$ 's of regressions in the bottom panel of Table 2 correspond to the "overall" $\mathrm{R}^{2}$ 's of the regressions of "unadjusted" loan growth on the linear and nonlinear capital ratio (distance) terms, and thus, they are directly comparable to the $\mathrm{R}^{2}$ 's in the top panel.

Note that the correlation between $\Delta l$ and $\triangle C A R D$ increases substantially when the quadratic term is included, particularly across banks where it reaches 0.40 - an increase of about 0.14 relative to the case in which only the linear $\triangle C A R D$ term is included. This suggests a nonlinear (quadratic) relation between $C A R D$ and loan growth, which will be explored in ARDL models below. 


\section{EMPIRICAL EVIDENCE}

The empirical mark-up equations described in section III are estimated using quarterly data on a pooled sample of 118 banks. The estimated models include four lags $(p=4)$ and are scrutinized for serial and cross-sectional dependence. Loan growth dynamics are explored with impulse response functions from a system of two nonlinear equations: the markup equation (6) or (8) and equation (9).

\section{A. Econometric Issues}

Care is needed in applying panel estimation techniques, as fixed-effects estimators can face two well-known potential problems: the inclusion of lagged dependent variables in the regression, and endogeneity associated with simultaneous equations.

Lagged dependent variable. The data "de-meaning" implicit in fixed-effects estimation introduces correlation between the error term and the lagged dependent regressor, that is, an endogeneity bias (Nickell, 1981). Several methods have been proposed to address this bias and relied on using valid (inside) instruments or generalized methods of moments (Anderson and Hsiao, 1981, Arellano and Bond, 1991, and others; for a recent survey, see Pesaran, 2015). These methods have proven quite useful, particularly for panel data samples characterized by short time dimensions. In this study, however, these estimation techniques are less relevant because of the long time dimension of the panel data set. Specifically, evidence from Monte Carlo studies (Judson and Owen, 1999) point to a reduction in the socalled Nickell bias as the time dimension increases, and report limited bias-typically 5 percent or less - when the panel data sample contains 30 or more time observations. Since the panel data sample here contains far more time observations, the bias is likely to be limited, and is subsequently ignored.

Simultaneous equations endogeneity. As noted in Section II, the monopolistic competition banking system consists of two simultaneous equations determining the lending rate and the quantity of loans. The error term in the empirical mark-up equation is thus expected to be correlated with the (contemporaneous) change in the lending rate, $\Delta i_{i, t}^{l}$. Instrumental variable techniques (two-stage fixed effects) are used to address the potential simultaneity bias with the theoretical framework presented above guiding the choice of economically meaningful instruments: variables that do not affect the bank's mark-up equation (5) but shift the loan demand curve (4), namely variables in $\Delta \boldsymbol{F}_{i, t}$.

Choice of instrumental variables. This study employs two (outside) instrumental variables: housing price inflation and bank-specific measures of Tobin's $Q$ for nonfinancial corporate borrowers. ${ }^{23}$ Housing prices affect loan demand through their impact on household wealth, credit constraints, and consumption, while Tobin's Q captures corporate loan demand. ${ }^{24}$

\footnotetext{
${ }^{23}$ See Appendix II for details on the construction of Tobin's Q measures for borrowers of individual banks.

${ }^{24}$ For the role of housing wealth in explaining consumption, both directly as well as through its effect on liquidity/credit constraints, see Lusardi and Mitchell (2007), Ong et al. (2013), and studies cited in the survey
} 
The potential drawback of employing Tobin's $Q$ as an instrument for corporate investment and loan demand is that it can also reflect financing constraints, that is, the supply of loans. The empirical literature finds that corporate investment is determined on the demand side by Tobin's Q - as a measure of business growth and investment opportunities - and on the supply side by "financing constraints." The latter have been proxied by cash flows, liquidity, and net worth (Hubbard, 1998; Fazzari, Hubbard, and Petersen, 1988) and are relevant for the firm's investment decision due to informational assymetries (agency or lemons problems) that create a gap between the cost of external and internal funds.

It can be argued, particularly for larger and more established firms, that loan supply shocks affect corporates' financing constraints leaving investment opportunities (and Tobin's Q) unchanged; but empirical evidence suggests that announcements of loan agreements between firms and banks have a significant effect on firms' stock prices and Tobin's Q (Gorton and Winton, 2003; and references therein). This, however, is more likely to become an issue for the use of Tobin's $Q$ as an instrument to the extent that it reflects data for smaller and less mature firms that lack the proven track record of larger and more established firms; all of the evidence suggests that the latter are less financially constrained. Since the Tobin's Q measurements here have been computed as the weighted average of Tobin's $Q$ for individual publicly traded firms - so that the largest and most transparent firms operating in Indonesia receive the largest weights (see Appendix II for details) - the instrument will reflect primarily the data of those firms where loan supply shocks are likely to leave investment opportunities unchanged. Indeed, standard statiscal tests confirm the validity of the instruments used in this paper.

\section{B. Empirical Results}

The empirical results for the "basic" and "extended" ARDL models are reported in Tables 35 , where long-run loan growth specifications progressively allow more flexibility. Coefficient estimates are reported as the sum of coefficients for the lagged and (when included) contemporaneous values of each right-hand side variable, with dynamics discussed in sub-section C. Estimates based on different estimation techniques are grouped in columns that for each right-hand side variable also report test results of whether: (1) the sum of its coefficients is zero, and (2) all of its coefficients are zero (exclusion from the model). A number of specification tests are also reported, including tests for serial correlation, crosssectional dependency, and, when appropriate, power of outside instruments in the "firststage" regression, exogeneity of "second stage" residuals, and the validity of the instruments' over-identification conditions.

\section{Results for the Basic Model: Time-invariant Long-run Loan Growth}

Table 3 presents results for the most restrictive (basic) model. Ordinary least square (OLS) estimates restrict long-run loan growth to be time-invariant and common across banks. In general, the signs of (sums of) estimated coefficients conform well with theoretical priors. Banks increase loan growth as bank-specific fundamentals improve, namely when NPLR

by Attanasio and Weber (2010). For the role of Tobin's Q and other variables in explaining business investment, see surveys by Chirinko (1993) and Jorgenson (1971), and the studies cited therein. 
falls, LATA increases, or $C A R D$ increases; in the latter case, there is a nonlinear effect whereby the impact of $C A R D$ becomes less pronounced as $C A R D$ increases. Likewise, loan growth increases when macroeconomic conditions improve (activity accelerates or inflation declines). There are, however, two notable exceptions: loan growth responses to changes in the nominal lending rate and the policy interest rate have the wrong sign. Taken literally, this implies that banks would increase loan growth when their interest rate spread declines (the lending rate decreases or the policy rate increases). Although all regressors are statistically significant, these regressions suffer from serial correlation of order four and exhibit crosssectional dependence (both at the 5 percent marginal significance level).

Fixed-effects (FE) estimates introduce bank-specific (time-invariant) long-run growth. The resulting estimates are qualitatively unchanged, including the perverse interest rate coefficients. Once again, all regressors are statistically significant even as serial correlation is no longer significant at the 5 percent level; cross-sectional dependence remains an issue.

Two-stage fixed-effects (2SFE) estimates employ house price inflation and bank-specific measures of Tobin's Q as (outside) instruments for the contemporaneous change in the nominal lending rate. The empirical results remain qualitatively unchanged, including the perverse effect of interest rates on bank loan growth; serial correlation is not significant at 5 percent but cross-sectional dependence remains significant.

The perverse signs of interest rate coefficients are not surprising because these are likely to be biased as the mark-up equation is part of a system of simultaneous equations. But what is surprising is that the problem remains even when instrumental variable estimation techniques are used. In other words, the data either appear to clash with the restrictive specification of the mark-up equation, or possibly and more generally, with the theoretical framework. Henceforth, regression analysis explores further these issues by considering less restrictive specifications of the mark-up equation.

\section{Results for the Extended Model: Time-Varying Long-Run Loan Growth}

Table 4 presents estimation results when long-run loan growth includes a common timevarying component, namely GDP growth, as well as a bank-specific time-invariant component (fixed-effects). ${ }^{25}$

Fixed effects estimates continue to result in coefficients with the expected effects on loan growth: banks increase loan growth as bank-specific fundamentals or macroeconomic conditions improve. As above, the loan growth responses to interest rates have the wrong sign. Note that the empirical model now separates the effects of GDP growth on loan growth between its impact on the long-run growth path (positive) and its impact on the transitional dynamics around this path (negative), with the latter dissipating over time. These estimates suggest that GDP growth has a powerful effect on long-run loan growth that far exceeds

\footnotetext{
${ }^{25}$ Note that including CPI inflation as an additional common time-varying component leaves the qualitative results unchanged. But the corresponding 2SFE fails the Wu-Hausman exogeneity test (details in Appendix III, Table 1.)
} 
unity. Serial correlation is not significant at the 5 percent significance level nor is crosssectional dependence.

Two stage fixed-effects estimates continue to suggest that loan growth increases when bankspecific fundamentals and macroeconomic conditions improve. But now the estimated coefficients for both interest rates have the expected sign: improvements in interest rate spreads - either due to increases in the lending rate or declines in the deposit rate - result in higher loan growth. Serial correlation is not significant at the 5 percent significance level but now cross-sectional dependence is.

Note that the instruments are significantly correlated with the change in lending rate as evidenced by the F-tests for the first stage regression. Moreover, the outside instruments (Tobin's Q and house price inflation) on their own are significantly correlated with the change in the lending rate (F-test for the first stage outside instruments). The Wu-Hausman test for exogeneity does not reject the null of exogeneity of the 2SLS residuals. And finally, the Hansen over-identification test does not reject the over-identification conditions for the 2SLS specification at the 5 percent marginal significance level. All these results point to the validity of the instruments employed.

The increased flexibility in the empirical mark-up equation, stemming from the addition of GDP growth as a long-run loan growth determinant, provides tantalizing results. Not surprisingly, long-run loan growth decisions by individual banks appear to depend on macroeconomic conditions. The introduction of GDP growth as a common source of time variation also allows the fixed-effects estimation to soak-up the cross-sectional dependence. For the instrumental variable estimates, adding GDP growth helps the instrumental variables to effectively control for loan demand shifts and thereby reverse the signs of the lending interest rate coefficients. But this improvement in 2SFE results comes at the expense of reintroducing cross-sectional dependence.

Table 5 extends the long-run loan growth specification by adding bank-specific factors consistent with the empirical mark-up equation (8). Specifically, the levels of NPLR, LATA, and $C A R D$ are now included as determinants of long-run loan growth, ${ }^{26}$ along with the fixed effects and GDP growth. With this added flexibility, the empirical model now allows for long-run loan growth variation across banks and over time.

As above, estimation results based on fixed effects are broadly consistent with bank's profitmaximizing behavior except for interest rates. A bank slows its long-run loan growth when NPLR increases - reflecting the need to reduce risk-weighted assets (de-lever) and thus offset the future impact of credit losses on capital ratios. A bank also slows its long-run loan growth when its liquidity $(L A T A)$ or capital $(C A R D)$ positions worsen, with the latter also including a non-linear effect. Specifically, the impact of $C A R D$ on long-run loan growth becomes more pronounced the closer the capital position is to its regulatory minimum requirement. Loan growth in a weaker bank is more sensitive to changes in its capital position than in a stronger

\footnotetext{
${ }^{26}$ In the regressions, these bank-specific factors are predetermined for loan growth in the corresponding quarter and so adding them to the augmented ARDL should not introduce a simultaneity bias.
} 
bank (this will be explored further below). Serial correlation of order 4 is significant at the 5 percent significance level but cross-sectional dependence is not.

Two-stage fixed effects estimates are qualitatively unchanged but the instrumental variables have effectively controlled for shifts in loan demand and reversed the sign of the lending interest rate coefficients: increases in the interest rate spread now result in higher loan growth. Serial correlation of order 4 is significant at the 5 percent significance level but cross-sectional dependence is not. Once again, standard tests support the validity of the instruments employed and overidentification conditions are not rejected at the 5 percent significance level. ${ }^{27}$

The inclusion of bank-specific long-run factors in the empirical mark-up equation has resulted in our preferred model. The presence of both common and bank-specific timevarying long-run factors allows two-stage fixed effects estimates to mop-up cross-sectional dependence and produces coefficient estimates that are consistent with the theoretical framework in Section II. ${ }^{28}$

In sum, the empirical evidence highlights the sensitivity of the results to: 1) the specification of long-run loan growth determinants; and 2) accounting for simultaneity bias. Specifically, estimates from regression not controlling for simultaneity consistently point to a perverse result that is inconsistent with profit maximizing behavior: increasing loan growth when the interest rate spread declines. Also, the use of instrumental variable techniques is ineffective in addressing this problem when long-run loan growth specifications are restrictive-namely, when they do not allow for time variation. Note that the use of two-stage fixed effects techniques also helped clear up cross-sectional dependence. Since instrumental variable techniques seek to "isolate" the mark-up equation estimates from the influence of demand side factors, it is likely that the cross-sectional dependence observed in fixed effects estimates is associated with fluctuations in loan demand. In other words, shifts in the loan demand curves faced by individual banks could be correlated due to the influence of common economy-wide factors. ${ }^{29}$

\section{Dynamic Responses}

This section compares the impulse responses of bank loan growth to capital shocks across different estimated model specifications. It then shows how, in the presence of nonlinear effects, mean-preserving redistributions of capital in the banking system can significantly

\footnotetext{
${ }^{27}$ Appendix III considers further the validity of the instruments by examining the robustness of the results when only one of the instruments is included in the estimation. Appendix III, Table 1 confirms that the results do not change qualitatively though the effect of the lending rate is lower (or higher) when only house price inflation (Tobin's Q) is used as the instrument. In either case, the instruments are significantly correlated with the lending rate, and the over-identification tests and the exogeneity of the second stage residuals are not rejected.

${ }^{28}$ However, note that some evidence of serial correlation of order 4 remains.

${ }^{29}$ Note that the intrinsic dynamics of loan growth (given by the sum of the lagged dependent variable coefficients) appears to be weak, and diminishes in strength as the long-run loan growth specification becomes more flexible. The sum of the lagged dependent variable coefficients is the highest for OLS estimates with a common time-invariant long-run loan growth (about 0.44 , Table 3 ); it is lower when long-run growth varies across banks (about 0.35 in Table 4 ) and lower still when the long-run growth varies across banks and over time (about 0.32 in Table 5).
} 
affect the response of aggregate lending to shocks. Impulse responses have been computed using a system of two nonlinear equations comprising the markup equation, namely equation (6) or (8), and equation (9). ${ }^{30}$

\section{Responses of Bank Loan Growth to Shocks for Different Estimated Model Specifications}

Figure 3 depicts impulse response functions for $\triangle C A R D$ shocks $\left(\omega_{i, t}^{C A R D}=1\right.$ percentage point in the first quarter of 2005, when $t=0$, and 0 otherwise), which reflect the nonlinear (quadratic) effect of $C A R D$ on loan growth. ${ }^{31}$ These impulse responses stem from three models with different long-run loan growth specifications: (1) bank-specific and time-invariant (Table 3, 2SFE), (2) time-varying with bank-specific fixed effects and a common macroeconomic component (Table 4, 2SFE), and (3) both common and bank-specific time-varying components (Table 5, 2SFE). For each model, 118 bank-specific impulse response functions for capital shocks were computed. Figure 3 summarizes the results with the median response for each quarter (with an equal number of individual bank impulse responses above and below) and with the range spanning the responses of 90 percent of the banks (106 banks), namely $5^{\text {th }}$ and $95^{\text {th }}$ percentile loan growth responses. ${ }^{32}$

The figure shows that the intensity and persistence of impulse responses change dramatically when the model specification becomes more flexible, thus highlighting the importance of including both common and bank-specific time-varying components as determinants of longrun loan growth. The responses described below correspond to the most general and preferred specification (Table 5, 2SFE).

According to the median response, the (quarterly) loan growth rate increases in the first six quarters (with some oscilation), and gradually declines thereafter. The (cumulative) effect of the shock results in the level of loans increasing by 0.8 percent after 8 quarters, and by 1.3 percent after 16 quarters. The $95^{\text {th }}$ percentile loan growth response is close to the median response, implying that a large number of banks increase their loan growth rates by similar amounts. The $5^{\text {th }}$ percentile loan growth response, however, is about half as large; the $C A R D$ shock increases the level of loans by 0.4 percent after 8 quarters, and by 0.7 percent after 16

\footnotetext{
${ }^{30}$ For the impulse response functions discussed below, capital shocks are obtained by setting $\Xi_{i}^{\mathrm{AVG}}=0.0124$ for $i=1,2, \ldots, 118$ in equation (9). This value corresponds to the estimated (common) intercept conditional on a "drag" coefficient of -1 . The data do not reject the null hypothesis of equality of intercept $\Xi_{i}^{\mathrm{AVG}}=\Xi^{\mathrm{AVG}}$ at conventional significance levels (see Appendix IV for details). Further, the qualitative results do not depend on the value of $\Xi^{\mathrm{AVG}}$ as it exerts second order (negligible) effects in the resulting impulse responses (see Appendix I for details).

${ }^{31}$ Confidence bands (not shown in Figure 3) are narrow, and hence, the dynamic effects discussed in the main text are measured fairly precisely. In particular, bootstrapping techniques were employed to gauge the uncertainty of the dynamic responses corresponding to the preferred model (Table 5, 2SFE) and equation (9) 1,000 bootstrap iterations were summarized by 90 percent "confidence" bands. Note, however, that confidence bands for impulse responses obtained from this two-equation model tend to be narrower than those obtained from vector autoregression (VAR) models. This is because the paths of right hand-side variables (other than capital ratio distance) are exogenous and constant rather than simulated as a part of a dynamic system.

${ }^{32}$ The median and the boundaries of the response range $\left(5^{\text {th }}\right.$ and $95^{\text {th }}$ percentile responses $)$ are "point" estimates backed out from the estimated ARDL model.
} 
quarters. This pattern reflects the historical distribution of capital ratio distance $(C A R D)$ across banks in the first quarter of 2005 and in the four quarters of 2014 (given the four lags included in the ARDL model).

\section{Bank Capital and Lending: Nonlinearity}

To illustrate the impact of the nonlinear effects that capital shocks have on a bank's loan growth response, impulse response functions are computed for hypothetical banks characterized by different initial $C A R D$ levels. "Initial $C A R D$ " is defined to include the history up to time $t=0$, and thus, (pre-shock) $C A R D$ levels at $t=0,-1,-2, \ldots$ differ across impulse responses.

As noted in the introduction, Figure 1 shows the effects of a one percentage point shock to capital ratios on lending at different time horizons for banks with different initial capital ratio distances (top) and the corresponding impulse responses of the capital ratio distance (bottom). The lending response of a bank that is undercapitalized by 5 percentage points after 12 or 16 quarters is roughly a third larger than that of a bank that is overcapitalized by 15 percentage points. Due to the drag effect of increased lending on capital ratio distance: the initial one percentage point increase in $C A R D$ declines over time, with the capital ratio returning to its initial level in about 16 quarters. The important qualitative insight drawn from Figure 1 is that the response of lending to a given capital shock size diminishes as the initial level of $C A R D$ increases, reflecting the nonlinearity of the model.

The numerical responses of lending after 4 quarters are similar in magnitude to those reported by Gambacorta and Shin (2016) for banks in advanced economies. Based on a linear model, they find that a one percentage point increase in the equity-to-total assets ratio increases the loan growth rate by 0.6 percentage points in the first year, with diminishing effects in subsequent years. ${ }^{33}$ In this paper, however, the lending effects of capital shocks intensify during the second and third years of the time horizon (Figures 1 and 3 ). Thus, cumulative lending responses at two- and three-year horizons here are markedly larger (about 40 percent) than those found by Gambacorta and Shin (2016).${ }^{34}$ It remains an open question whether this difference reflects their more restrictive model specification-which does not disentangle transitional dynamics from long-run growth — or stronger lending responses of Indonesia's banks compared to those of banks in advanced economies.

\footnotetext{
${ }^{33}$ In contrast to Gambacorta and Shin (2016), shocks in this paper are applied to risk weighted measures of capitalization. Thus, to better compare results across the two studies, the shocks in this paper must be re-scaled (multiplied by an average ratio of total assets-to-risk weighted assets of 1.7).

${ }^{34}$ In this study, for a bank with $C A R D$ equal to zero, a one percentage point shock to the capital-to-assets ratio increases lending by 1.6 percent over two years compared to (less than) 1.2 percent in advanced economies (Gambacorta and Shin, 2016). Note that Gambarcorta and Shin do not report the responses of loan growth rates after the first year; however, from their autoregresive specification, we infer that the response in the second year would be smaller than in the first year ( 0.6 percent), and hence, the cumulative response at a two-year horizon would be smaller than 1.2 percent.
} 
Figure 4 shows how the size and sign of a capital shock affects the response of loan growth for a hypothetical bank with "average capital," defined as a bank whose $C A R D$ corresponds to the average $C A R D$ across all banks.

The figure illustrates that impulse responses depend on the size of the shock. The lending response to a +10 percentage point capital shock is less than 10 times stronger than the response to a +1 percentage point shock. But the response to a -10 percentage point $C A R D$ shock exceeds 10 times (in absolute value) the response to a -1 percentage point shock. Thus, for positive capital shocks the nonlinearity implies diminishing "marginal" effects of capital shock size on loan growth; for negative shocks, in contrast, the marginal effects of capital shocks on loan growth increase (in absolute value) with the size of the shock.

Relatedly, the figure shows that impulse responses are asymmetric as they depend on the sign of the shock. The response to a -10 percentage point shock is not a mirror image of the response corresponding to a +10 percentage point shock: negative capital shocks result in larger responses (in absolute value) than positive shocks of equal size.

\section{Bank Capital Heterogeneity and the Effects of Capital Shocks on Aggregate Lending}

To highlight the importance of accounting for bank capital heterogeneity when quantifying the effects of shocks on "aggregate" (economy-wide) lending, Figure 5 illustrates how a (hypothetical) "mean-preserving" re-distribution of capital in the system would affect the impulse response of aggregate lending to capital shocks. In this thought experiment, aggregate lending is computed as a weighted average of the 118 bank-specific impulse responses using as weights the shares of banks' loans in the banking system.

As above, capital shocks materialize in the first quarter of 2005 and the aggregate loan growth responses are computed for two cases. The first serves as a "reference" as it employs the historical panel data and reflects the historical distribution of $C A R D$ ratios across banks. In this case, the aggregate lending response is calculated from the individual bank responses underlying Figure 3. The second case corresponds to a hypothetical banking system in which all banks have the same CARD level (equal to the banking system's average). What emerges from this illustration is that, compared to the hypothetical banking system, the historical responses of "aggregate" loan growth rates were consistently larger (by 11 percent). In other words, a lower degree of heterogeneity in capitalization ratios across banks can increase the resilience of aggregate lending to capital (solvency) shocks. Note, however, that this result depends on the distribution of bank capital in Indonesia (particularly among the largest banks). ${ }^{35}$

\footnotetext{
${ }^{35}$ In the first quarter of 2005, the distribution of $C A R D$ values across banks exhibited both positive skewness and (excess) kurtosis. When CARD is set equal to the system's average for all banks, most banks would have higher CARD levels than those that they actually had in the first quarter of 2005. And, as illustrated in Figure 1, strongly capitalized banks respond less to CARD shocks than weakly capitalized banks.
} 


\section{CONCLUding ReMARKS}

This paper studies the transmission of bank capital shocks to loan supply in Indonesia. A theoretically-founded mark-up equation for a monopolistic competitive bank is derived and used to formulate an empirical model. Based on a unique dataset, the estimated equation disentangles the determinants of bank loan growth into components that affect its long-run path from those that only influence the transitional dynamics. The effects of capital shocks on loan growth and capital ratios stem from a system of two nonlinear equations. The paper finds significant nonlinear effects of bank capital on lending: the response of weaker banks to a positive capital shock is larger than that of stronger banks. Non-linearities imply that not only the level but also the distribution of capital across banks in the system affects the transmission of shocks to aggregate lending. Also, the effects of bank recapitalization on loan growth depend on starting capital positions and the size of capital injections. 


\section{Table 1. Summary Statistics of the Panel Data (in percent, unless otherwise indicated)}

\begin{tabular}{|c|c|c|c|c|c|c|}
\hline Variable & Mean & $\begin{array}{l}\text { Standard } \\
\text { deviation }\end{array}$ & $\begin{array}{c}\text { First } \\
\text { quartile }\end{array}$ & Median & $\begin{array}{c}\text { Third } \\
\text { quartile }\end{array}$ & $\begin{array}{c}\text { Number of } \\
\text { observations }\end{array}$ \\
\hline \multicolumn{7}{|l|}{ Dependent variable and short-run dynamic effects } \\
\hline \multicolumn{7}{|l|}{ Dependent variable } \\
\hline Real loan growth: $\Delta l_{i, t}$ & 4.43 & 12.42 & -1.41 & 3.26 & 8.40 & 6418 \\
\hline \multicolumn{7}{|l|}{ Change in nominal lending rate } \\
\hline Change in nominal lending rate: $\Delta i_{i, t-s}^{l}$ & -0.07 & 1.23 & -0.34 & -0.08 & 0.16 & 6418 \\
\hline \multicolumn{7}{|l|}{ Change in bank specific fundamentals } \\
\hline Change in non-performing loan ratio: $\triangle N P L R_{i, t-s}$ & -0.19 & 2.71 & -0.40 & -0.02 & 0.24 & 6418 \\
\hline Change in liquid assets ratio: $\triangle L A T A_{i, t-s}$ & -0.24 & 26.66 & -5.15 & -0.28 & 4.35 & 6418 \\
\hline Change in capital ratio distance: $\triangle C A R D_{i, t-s}$ & -0.19 & 8.66 & -1.69 & -0.22 & 1.20 & 6418 \\
\hline \multicolumn{7}{|l|}{ Change in macroeconomic variables (common effects) } \\
\hline Change in policy rate: $\Delta i_{t-s}^{d}$ & -0.13 & 0.79 & -0.58 & 0.00 & 0.17 & 6418 \\
\hline Change in real GDP growth: $\triangle R G D P G_{t-s}$ & -0.02 & 3.66 & -3.60 & 0.64 & 1.73 & 6418 \\
\hline Change in inflation rate: $\Delta I N F_{t-s}$ & -0.05 & 2.22 & -1.03 & 0.12 & 1.00 & 6418 \\
\hline \multicolumn{7}{|l|}{ Long-run effects } \\
\hline \multicolumn{7}{|l|}{ Bank-specific } \\
\hline Non-performing loan ratio: $N P L R_{i, t-1}$ & 4.27 & 6.80 & 1.15 & 2.43 & 4.34 & 6418 \\
\hline Liquid assets ratio: $L A T A_{i, t-1}$ & 32.25 & 45.00 & 13.19 & 22.14 & 35.96 & 6418 \\
\hline Capital ratio distance: $C A R D_{i, t-1}$ & 18.02 & 24.44 & 6.30 & 10.68 & 18.64 & 6418 \\
\hline \multicolumn{7}{|l|}{ Macroeconomic (common) } \\
\hline Real GDP growth: $R G D P G_{t}$ & 1.34 & 2.23 & -0.82 & 2.05 & 2.86 & 6418 \\
\hline
\end{tabular}

Source: Bank Indonesia and author's calculations. Note. Summary statistics are computed with the available quarterly observations from 2001:Q1 to 2015:Q1 for 118 banks operating at end-2015. To minimize the influence of outliers, the banking data were first winsorized at the 1 and 99 percent levels. (As noted in the text, the panel data is unbalanced due to its granular nature.) 
Table 2. Pairwise Regressions of Loan Growth and “Adjusted” Loan Growth on Changes in Capital Ratio Distance

\begin{tabular}{|c|c|c|c|c|c|c|c|c|}
\hline \multirow[b]{2}{*}{ Dependent variable: Real loan growth: $\Delta l_{i, t}$} & \multicolumn{4}{|c|}{ Based on Time Averages for Each of the 118 banks } & \multicolumn{4}{|c|}{ Based on Cross-bank Averages for Each of the 54 Quarters } \\
\hline & Intercept & Slope (p-value) & $R^{2}$ & $\begin{array}{c}\text { Number of } \\
\text { observations }\end{array}$ & Intercept & Slope (p-value) & $R^{2}$ & $\begin{array}{c}\text { Number of } \\
\text { observations }\end{array}$ \\
\hline Change in capital ratio distance: $\triangle C A R D_{i, t}$ & 0.04 & $-1.63 \quad(0.00)$ & 0.26 & 118 & 0.04 & $-0.55 \quad(0.02)$ & 0.10 & 55 \\
\hline $\begin{array}{l}\text { Dependent variable: Adjusted real loan growth: } \\
\qquad \Delta l_{i, t}-\text { Intercept }- \text { Slope } \cdot \Delta C A R D_{i, t}\end{array}$ & & Slope (p-value) & $R^{2}$ & $\begin{array}{c}\text { Number of } \\
\text { observations }\end{array}$ & & Slope (p-value) & $R^{2}$ & $\begin{array}{l}\text { Number of } \\
\text { observations }\end{array}$ \\
\hline Change in capital ratio distance squared: $\triangle C A R D_{i, t}^{2}$ & & $33.62(0.00)$ & 0.40 & 118 & & $-9.98 \quad(0.29)$ & 0.12 & 55 \\
\hline
\end{tabular}

Source: Bank Indonesia and authors' calculations. Note. The estimated coefficients are obtained using OLS estimation based on 118 (55) time (cross-bank) average observations as indicated. The reported $\mathrm{R}^{2}$ are directly comparable as these reflect the linear (linear and nonlinear) effect when the dependent variable is real loan growth (adjusted real loan growth). 
Table 3. Response of Loan Growth to Changes in Bank-specific Fundamentals and Macroeconomic Variables: Basic Model with Constant Long-Run Growth (Eq. 6)

\begin{tabular}{|c|c|c|c|c|c|c|c|c|c|c|}
\hline \multirow[b]{3}{*}{ Dependent variable: Real loan growth: $\Delta l_{i, t}$} & \multirow{3}{*}{$\begin{array}{c}\text { Lags } \\
\text { included: } \\
S\end{array}$} & \multicolumn{3}{|c|}{ Ordinary least squares estimation } & \multicolumn{3}{|c|}{ Fixed-effects estimation } & \multicolumn{3}{|c|}{ Two-stage fixed-effects estimation } \\
\hline & & \multirow{2}{*}{$\begin{array}{c}\text { Sum of } \\
\text { coefficient } \\
\text { estimates }\end{array}$} & \multicolumn{2}{|c|}{ Hypothesis tests } & \multirow{2}{*}{$\begin{array}{c}\text { Sum of } \\
\text { coefficient } \\
\text { estimates }\end{array}$} & \multicolumn{2}{|c|}{ Hypothesis tests } & \multirow{2}{*}{$\begin{array}{c}\text { Sum of } \\
\text { coefficient } \\
\text { estimates }\end{array}$} & \multicolumn{2}{|c|}{ Hypothesis tests } \\
\hline & & & $\begin{array}{l}\text { Sum equals zero } \\
\text { ( } p \text {-value })\end{array}$ & $\begin{array}{c}\text { Exclusion test } \\
\text { (p-value) }\end{array}$ & & $\begin{array}{l}\text { Sum equals zero } \\
\text { ( } p \text {-value })\end{array}$ & $\begin{array}{l}\text { Exclusion test } \\
\text { (p-value) }\end{array}$ & & $\begin{array}{l}\text { Sum equals zero } \\
\text { (p-value) }\end{array}$ & $\begin{array}{l}\text { Exclusion test } \\
\text { (p-value) }\end{array}$ \\
\hline \multicolumn{11}{|l|}{ Short-run dynamic effects } \\
\hline \multicolumn{11}{|l|}{ Lagged dependent variable } \\
\hline Real loan growth: $\Delta l_{i, t-s}$ & 1 to 4 & 0.437 & $20.3(0.00)$ & $119.0(0.00)$ & 0.364 & $15.9(0.00)$ & $78.2(0.00)$ & 0.365 & $15.6(0.00)$ & $78.2(0.00)$ \\
\hline \multicolumn{11}{|l|}{ Change in nominal lending rate } \\
\hline Change in nominal lending rate: $\Delta i_{i, t-s}^{l}$ & 0 to 4 & -1.215 & $-3.9(0.00)$ & $12.3(0.00)$ & -1.310 & $-4.1(0.00)$ & $12.2(0.00)$ & -1.482 & $-0.9(0.39)$ & $6.7(0.00)$ \\
\hline \multicolumn{11}{|l|}{ Change in bank specific fundamentals } \\
\hline Change in non-performing loan ratio: $\triangle N P L R_{i, t-s}$ & 1 to 5 & -0.838 & $-5.9(0.00)$ & $13.5(0.00)$ & -0.880 & $-6.0(0.00)$ & $13.7(0.00)$ & -0.888 & $-5.4(0.00)$ & $10.7(0.00)$ \\
\hline Change in liquid assets ratio: $\triangle L A T A_{i, t-s}$ & 1 to 5 & 0.051 & $2.9(0.00)$ & $2.7(0.02)$ & 0.043 & $2.4(0.02)$ & $2.0(0.07)$ & 0.042 & $2.2(0.03)$ & $1.9(0.09)$ \\
\hline Change in capital ratio distance: $\triangle C A R D_{i, t-s}$ & 1 to 5 & 0.114 & $1.1(0.27)$ & $3.4(0.00)$ & 0.068 & $0.7(0.51)$ & $3.3(0.01)$ & 0.070 & $0.7(0.50)$ & $3.1(0.01)$ \\
\hline Change in capital ratio distance squared: $\triangle C A R D_{i, t-s}^{2}$ & 1 to 5 & -0.146 & $-2.2(0.03)$ & $2.4(0.03)$ & -0.129 & $-1.9(0.06)$ & $2.2(0.05)$ & -0.130 & $-1.9(0.06)$ & $2.2(0.05)$ \\
\hline \multicolumn{11}{|l|}{ Change in macroeconomic variables (common effects) } \\
\hline Change in policy rate: $\Delta t_{t-s}^{d}$ & 0 to 4 & 0.058 & $0.2(0.88)$ & $3.2(0.01)$ & 0.012 & $0.0(0.97)$ & $3.3(0.01)$ & 0.078 & $0.1(0.92)$ & $2.6(0.02)$ \\
\hline Change in real GDP growth: $\triangle R G D P G_{t-s}$ & 0 to 4 & 6.644 & $3.5(0.00)$ & $15.5(0.00)$ & 6.440 & $3.4(0.00)$ & $15.3(0.00)$ & 6.231 & $2.2(0.02)$ & $14.7(0.00)$ \\
\hline Change in inflation rate: $\Delta I N F_{t-s}$ & 0 to 4 & -3.284 & $-3.9(0.00)$ & $15.8(0.00)$ & -3.306 & $-3.9(0.00)$ & $15.4(0.00)$ & -3.292 & $-3.9(0.00)$ & $15.4(0.00)$ \\
\hline Adjusted $\mathrm{R}^{2}$ & & 0.140 & & & 0.139 & & & 0.139 & & \\
\hline Standard error of the regression & & 0.111 & & & 0.111 & & & 0.111 & & \\
\hline Number of observations & & 5786 & & & 5786 & & & 5786 & & \\
\hline \multicolumn{11}{|l|}{ Memo items } \\
\hline \multicolumn{11}{|l|}{ Lagragian Multiplier test for serial correlation } \\
\hline Order 1 & & 0.43 & $(0.67)$ & & 0.44 & (0.66) & & 0.46 & $(0.65)$ & \\
\hline Order 2 & & 0.06 & $(0.95)$ & & 0.12 & (0.91) & & 0.12 & (0.91) & \\
\hline Order 3 & & -0.29 & $(0.77)$ & & -0.14 & $(0.89)$ & & -0.13 & $(0.90)$ & \\
\hline Order 4 & & -2.06 & $(0.04)$ & & -1.88 & $(0.06)$ & & -1.89 & $(0.06)$ & \\
\hline F-test for first stage regression & & $\ldots$ & $\ldots$ & & $\ldots$ & $\ldots$ & & 15.02 & $(0.00)$ & \\
\hline F-test for first stage outside instruments & & $\ldots$ & $\ldots$ & & $\ldots$ & $\ldots$ & & 7.30 & $(0.00)$ & \\
\hline Wu-Hausman exogeneity test & & ... & $\ldots$ & & $\ldots$ & $\ldots$ & & 3.18 & $(0.07)$ & \\
\hline Hansen over-identification test & & $\ldots$ & $\ldots$ & & $\ldots$ & $\ldots$ & & 0.18 & $(1.00)$ & \\
\hline Pesaran cross-sectional dependence test & & 6.19 & $(0.00)$ & & 6.59 & $(0.00)$ & & 6.29 & $(0.00)$ & \\
\hline
\end{tabular}

Source: Bank Indonesia and authors' calculations. Note. Pooled panel estimates correspond to either OLS, fixed effects, or two-stage fixed effects estimators as indicated. The latter includes two sets of outside instruments, namely Tobin's $Q$ and housing price inflation. All estimates are based on an unbalanced panel of quarterly data from 2001:Q1 to 2015:Q1 for 118 banks operating in Indonesia at end-2015. The estimated augmented ARDL models contain the contemporaneous and lagged observations for the regressors as indicated; with the exception of the long-run effect of regressors, coefficient estimates have been summarized by their sum. In this regard, two null hypothesis test are reported for each regressor: (1) the sum of coefficients equals zero, and (2) every coefficient is equals zero. The table also reports a series of specification tests for all regressions: (1) absence of serial correlation of orders 1 to 4 ; and (2) lack of cross-sectional dependence. And for 2 SFE a series of additional tests are reported: (1) all coefficients in the "first-stage" regression are zero; (2) all coefficients of the outside instruments are zero; and (3) instruments are valid (orthogonal to the residuals). In all cases, the null hypothesis is rejected at the $5(10)$ percent significance level whenever the p-value (marginal significance level) is less than 5 (10) percent. 


\begin{tabular}{|c|c|c|c|c|c|c|c|}
\hline \multirow[b]{3}{*}{ Dependent variable: Real loan growth: $\Delta l_{i, t}$} & \multirow{3}{*}{$\begin{array}{c}\text { Lags } \\
\text { included: } \\
\end{array}$} & \multicolumn{3}{|c|}{ Fixed-effects estimation } & \multicolumn{3}{|c|}{ Two-stage fixed-effects estimation } \\
\hline & & \multirow{2}{*}{$\begin{array}{c}\text { Sum of } \\
\text { coefficient } \\
\text { estimates }\end{array}$} & \multicolumn{2}{|c|}{ Hypothesis tests } & \multirow{2}{*}{$\begin{array}{c}\text { Sum of } \\
\text { coefficient } \\
\text { estimates }\end{array}$} & \multicolumn{2}{|c|}{ Hypothesis tests } \\
\hline & & & $\begin{array}{c}\text { Sum equals zero } \\
(p \text {-value })\end{array}$ & $\begin{array}{c}\text { Exclusion test } \\
\text { (p-value) }\end{array}$ & & $\begin{array}{c}\text { Sum equals zero } \\
\text { (p-value) }\end{array}$ & $\begin{array}{c}\text { Exclusion test } \\
\text { (p-value) }\end{array}$ \\
\hline \multicolumn{8}{|l|}{ Short-run dynamic effects } \\
\hline \multicolumn{8}{|l|}{ Lagged dependent variable } \\
\hline Real loan growth: $\Delta l_{i, t-s}$ & 1 to 4 & 0.357 & $15.5(0.00)$ & $75.0(0.00)$ & 0.346 & $14.0(0.00)$ & $68.6(0.00)$ \\
\hline \multicolumn{8}{|l|}{ Change in nominal lending rate } \\
\hline Change in nominal lending rate: $\Delta i_{i, t-s}^{l}$ & 0 to 4 & -1.049 & $-3.3(0.00)$ & $11.2(0.00)$ & 2.471 & $1.1(0.25)$ & $6.1(0.00)$ \\
\hline \multicolumn{8}{|l|}{ Change in bank specific fundamentals } \\
\hline Change in non-performing loan ratio: $\triangle N P L R_{i, t-s}$ & 1 to 5 & -0.904 & $-6.2(0.00)$ & $13.8(0.00)$ & -0.756 & $-4.3(0.00)$ & $7.8(0.00)$ \\
\hline Change in liquid assets ratio: $\triangle L A T A_{i, t-s}$ & 1 to 5 & 0.043 & $2.4(0.01)$ & $1.9(0.10)$ & 0.060 & $2.9(0.00)$ & $2.2(0.05)$ \\
\hline Change in capital ratio distance: $\triangle C A R D_{i, t-s}$ & 1 to 5 & 0.061 & $0.6(0.55)$ & $3.3(0.01)$ & 0.020 & $0.2(0.86)$ & $3.6(0.00)$ \\
\hline Change in capital ratio distance squared: $\triangle C A R D_{i, t-s}^{2}$ & 1 to 5 & -0.127 & $-1.9(0.06)$ & $2.2(0.05)$ & -0.120 & $-1.7(0.09)$ & $2.5(0.03)$ \\
\hline \multicolumn{8}{|l|}{ Change in macroeconomic variables (common effects) } \\
\hline Change in policy rate: $\Delta i_{t-s}^{d}$ & 0 to 4 & -0.485 & $-1.3(0.21)$ & $3.3(0.01)$ & -1.922 & $-2.0(0.04)$ & $2.8(0.02)$ \\
\hline Change in real GDP growth: $\triangle R G D P G_{t-s}$ & 0 to 4 & -6.778 & $-2.2(0.03)$ & $17.5(0.00)$ & -5.815 & $-1.8(0.08)$ & $16.0(0.00)$ \\
\hline Change in inflation rate: $\Delta I N F_{t-s}$ & 0 to 4 & -3.025 & $-3.6(0.00)$ & $14.8(0.00)$ & -3.231 & $-3.7(0.00)$ & $14.0(0.00)$ \\
\hline \multicolumn{8}{|l|}{ Long-run effects } \\
\hline \multicolumn{8}{|l|}{ Macroconomic (common) } \\
\hline Real GDP growth: $R G D P G_{t}$ & 0 & 5.298 & $5.3(0.00)$ & $28.3(0.00)$ & 6.589 & $5.1(0.00)$ & $25.8(0.00)$ \\
\hline Adjusted $R^{2}$ & & 0.143 & & & 0.143 & & \\
\hline Standard error of the regression & & 0.111 & & & 0.116 & & \\
\hline Number of observations & & 5786 & & & 5786 & & \\
\hline \multicolumn{8}{|l|}{ Memo items } \\
\hline \multicolumn{8}{|l|}{ Lagragian Multiplier test for serial correlation } \\
\hline Order 1 & & 0.38 & (0.71) & & 0.11 & $(0.92)$ & \\
\hline Order 2 & & 0.18 & $(0.86)$ & & 0.17 & $(0.87)$ & \\
\hline Order 3 & & -0.15 & $(0.88)$ & & -0.31 & $(0.76)$ & \\
\hline Order 4 & & -1.81 & $(0.07)$ & & -1.64 & $(0.10)$ & \\
\hline F-test for first stage regression & & ... & $\ldots$ & & 14.83 & $(0.00)$ & \\
\hline F-test for first stage outside instruments & & ... & ... & & 5.11 & $(0.00)$ & \\
\hline Wu-Hausman exogeneity test & & ... & ... & & 1.96 & $(0.16)$ & \\
\hline Hansen over-identification test & & ... & $\ldots$ & & 0.20 & $(1.00)$ & \\
\hline Pesaran cross-sectional dependence test & & 1.64 & (0.10) & & 3.50 & $(0.00)$ & \\
\hline
\end{tabular}

Source: Bank Indonesia and authors' calculations. Note. As indicated, pooled panel estimates correspond to either fixed effects or two-stage fixed effects estimators. The latter includes two sets of outside instruments, namely Tobin's Q and housing price inflation. All estimates are based on an unbalanced panel of quarterly data from 2001:Q1 to 2015:Q1 for 118 banks operating in Indonesia at end-2015. The estimated augmented ARDL models contain the contemporaneous and lagged observations for the regressors as indicated; with the exception of the long-run effect of regressors, coefficient estimates have been summarized by their sum. In this regard, two null hypothesis test are reported for each regressor: (1) the sum of coefficients equals zero, and (2) every coefficient is equals zero. The table also reports a series of specification tests for all regressions: (1) absence of serial correlation of orders 1 to 4; and (2) lack of cross-sectional dependence. And for 2SFE a series of additional tests are reported: (1) all coefficients in the "first-stage" regression are zero; (2) all coefficients of the outside instruments are zero; and (3) instruments are valid (orthogonal to the residuals). In all cases, the null hypothesis is rejected at the 5 (10) percent significance level whenever the p-value (marginal significance level) is less than 5

(10) percent. 


\section{Table 5. Response of Loan Growth to Changes in Bank-Specific Fundamentals and Macroeconomic Variables: Extended Model with Long-Run Growth Determined by Macroeconomic Variables and Levels of Bank-specific Fundamentals (Eq. 8)}

\begin{tabular}{|c|c|c|c|c|c|c|c|}
\hline \multirow[b]{3}{*}{ Dependent variable: Real loan growth: $\Delta l_{i, t}$} & \multirow[b]{3}{*}{$\begin{array}{c}\text { Lags } \\
\text { included: } \\
S\end{array}$} & \multicolumn{3}{|c|}{ Fixed-effects estimation } & \multicolumn{3}{|c|}{ Two-stage fixed-effects estimation } \\
\hline & & \multirow{2}{*}{$\begin{array}{c}\text { Sum of } \\
\text { coefficient } \\
\text { estimates }\end{array}$} & \multicolumn{2}{|c|}{ Hypothesis tests } & \multirow{2}{*}{$\begin{array}{c}\text { Sum of } \\
\text { coefficient } \\
\text { estimates }\end{array}$} & \multicolumn{2}{|c|}{ Hypothesis tests } \\
\hline & & & $\begin{array}{l}\text { Sum equals zero } \\
(p \text {-value })\end{array}$ & $\begin{array}{c}\text { Exclusion test } \\
\text { (p-value) }\end{array}$ & & $\begin{array}{c}\text { Sum equals zero } \\
\text { ( } p \text {-value })\end{array}$ & $\begin{array}{c}\text { Exclusion test } \\
\text { (p-value) }\end{array}$ \\
\hline \multicolumn{8}{|l|}{ Short-run dynamic effects } \\
\hline \multicolumn{8}{|l|}{ Lagged dependent variable } \\
\hline Real loan growth: $\Delta l_{i, t-s}$ & 1 to 4 & 0.324 & $13.8(0.00)$ & $59.2(0.00)$ & 0.314 & $12.5(0.00)$ & $55.0(0.00)$ \\
\hline \multicolumn{8}{|l|}{ Change in nominal lending rate } \\
\hline Change in nominal lending rate: $\Delta i_{i, t-s}^{l}$ & 0 to 4 & -1.049 & $-3.3(0.00)$ & $11.3(0.00)$ & 1.799 & $0.8(0.40)$ & $6.2(0.00)$ \\
\hline \multicolumn{8}{|l|}{ Change in bank specific fundamentals } \\
\hline Change in non-performing loan ratio: $\triangle N P L R_{i, t-s}$ & 1 to 5 & -0.690 & $-4.6(0.00)$ & $10.5(0.00)$ & -0.559 & $-3.1(0.00)$ & $6.1(0.00)$ \\
\hline Change in liquid assets ratio: $\triangle L A T A_{i, t-s}$ & 1 to 5 & -0.019 & $-0.8(0.42)$ & $0.4(0.86)$ & -0.005 & $-0.2(0.84)$ & $0.1(0.99)$ \\
\hline Change in capital ratio distance: $\triangle C A R D_{i, t-s}$ & 1 to 5 & -0.415 & $-3.4(0.00)$ & $5.1(0.00)$ & -0.437 & $-3.5(0.00)$ & $5.1(0.00)$ \\
\hline Change in capital ratio distance squared: $\triangle C A R D_{i, t-s}^{2}$ & 1 to 5 & 0.031 & $0.4(0.70)$ & $1.1(0.34)$ & 0.027 & $0.3(0.75)$ & $1.4(0.23)$ \\
\hline \multicolumn{8}{|l|}{ Change in macroeconomic variables (common effects) } \\
\hline Change in policy rate: $\Delta i_{t-s}^{d}$ & 0 to 4 & -0.340 & $-0.9(0.38)$ & $2.6(0.03)$ & -1.523 & $-1.6(0.11)$ & $2.4(0.04)$ \\
\hline Change in real GDP growth: $\triangle R G D P G_{t-s}$ & 0 to 4 & -6.706 & $-2.2(0.03)$ & $16.0(0.00)$ & -5.842 & $-1.8(0.07)$ & $14.9(0.00)$ \\
\hline Change in inflation rate: $\Delta I N F_{t-s}$ & 0 to 4 & -2.625 & $-3.2(0.00)$ & $14.7(0.00)$ & -2.776 & $-3.2(0.00)$ & $14.1(0.00)$ \\
\hline \multicolumn{8}{|l|}{ Long-run effects } \\
\hline \multicolumn{8}{|l|}{ Bank-specific } \\
\hline Non-performing loan ratio: $N P L R_{i, t-1}$ & 1 & -0.081 & $-2.5(0.01)$ & $6.1(0.01)$ & -0.090 & $-2.6(0.01)$ & $6.8(0.01)$ \\
\hline Liquid assets ratio: $L A T A_{i, t-1}$ & 1 & 0.026 & $3.9(0.00)$ & $14.8(0.00)$ & 0.026 & $3.7(0.00)$ & $13.9(0.00)$ \\
\hline Capital ratio distance: $C A R D_{i, t-1}$ & 1 & 0.195 & $7.2(0.00)$ & $52.2(0.00)$ & 0.191 & $6.8(0.00)$ & $46.5(0.00)$ \\
\hline Capital ratio distance squared: $C A R D_{i, t-1}^{2}$ & 1 & -0.070 & $-3.7(0.00)$ & $13.8(0.00)$ & -0.066 & $-3.4(0.00)$ & $11.4(0.00)$ \\
\hline \multicolumn{8}{|l|}{ Macroeconomic (common) } \\
\hline Real GDP growth: $R G D P G_{t}$ & 0 & 4.929 & $5.0(0.00)$ & $24.8(0.00)$ & 5.945 & $4.7(0.00)$ & $22.1(0.00)$ \\
\hline Adjusted $\mathrm{R}^{2}$ & & 0.166 & & & 0.166 & & \\
\hline Standard error of the regression & & 0.110 & & & 0.113 & & \\
\hline Number of observations & & 5786 & & & 5786 & & \\
\hline \multicolumn{8}{|l|}{ Memo items } \\
\hline \multicolumn{8}{|l|}{ Lagragian Multiplier test for serial correlation } \\
\hline Order 1 & & 0.61 & $(0.54)$ & & 0.34 & $(0.73)$ & \\
\hline Order 2 & & 0.21 & $(0.84)$ & & 0.19 & $(0.85)$ & \\
\hline Order 3 & & -0.38 & $(0.70)$ & & -0.51 & $(0.61)$ & \\
\hline Order 4 & & -2.08 & $(0.04)$ & & -1.95 & $(0.05)$ & \\
\hline F-test for first stage regression & & $\ldots$ & $\ldots$ & & 13.77 & $(0.00)$ & \\
\hline F-test for first stage outside instruments & & $\ldots$ & $\ldots$ & & 4.95 & $(0.00)$ & \\
\hline Wu-Hausman exogeneity test & & $\ldots$ & $\ldots$ & & 1.93 & $(0.17)$ & \\
\hline Hansen over-identification test & & $\ldots$ & $\ldots$ & & 0.32 & $(1.00)$ & \\
\hline Pesaran cross-sectional dependence test & & 1.08 & $(0.28)$ & & 1.57 & $(0.12)$ & \\
\hline
\end{tabular}

Source: Bank Indonesia and authors' calculations. Note. As indicated, pooled panel estimates correspond to either fixed effects or two-stage fixed effects estimators. The latter includes two sets of outside instruments, namely Tobin's Q and housing price inflation. All estimates are based on an unbalanced panel of quarterly data from 2001:Q1 to 2015:Q1 for 118 banks operating in Indonesia at end-2015. The estimated augmented ARDL models contain the contemporaneous and lagged observations for the regressors as indicated; with the exception of the long-run effect of regressors, coefficient estimates have been summarized by their sum. In this regard, two null hypothesis test are reported for each regressor: (1) the sum of coefficients equals zero, and (2) every coefficient is equals zero. The table also reports a series of specification tests for all regressions: (1) absence of serial correlation of orders 1 to 4; and (2) lack of cross-sectional dependence. And for 2SFE a series of additional tests are reported: (1) all coefficients in the "first-stage" regression are zero; (2) all coefficients of the outside instruments are zero; and (3) instruments are valid (orthogonal to the residuals). In all cases, the null hypothesis is rejected at the 5 (10) percent significance level whenever the p-value (marginal significance level) is less than 5 (10) percent. 
Figure 1. Cumulative Responses of Loan Growth and Capital Ratio Distances to a +1 Percentage Point Shock to Capital Ratios at Different Time Horizons, for Banks with Different Initial Capital Ratio Distances (Eq. 8 and Eq. 9)

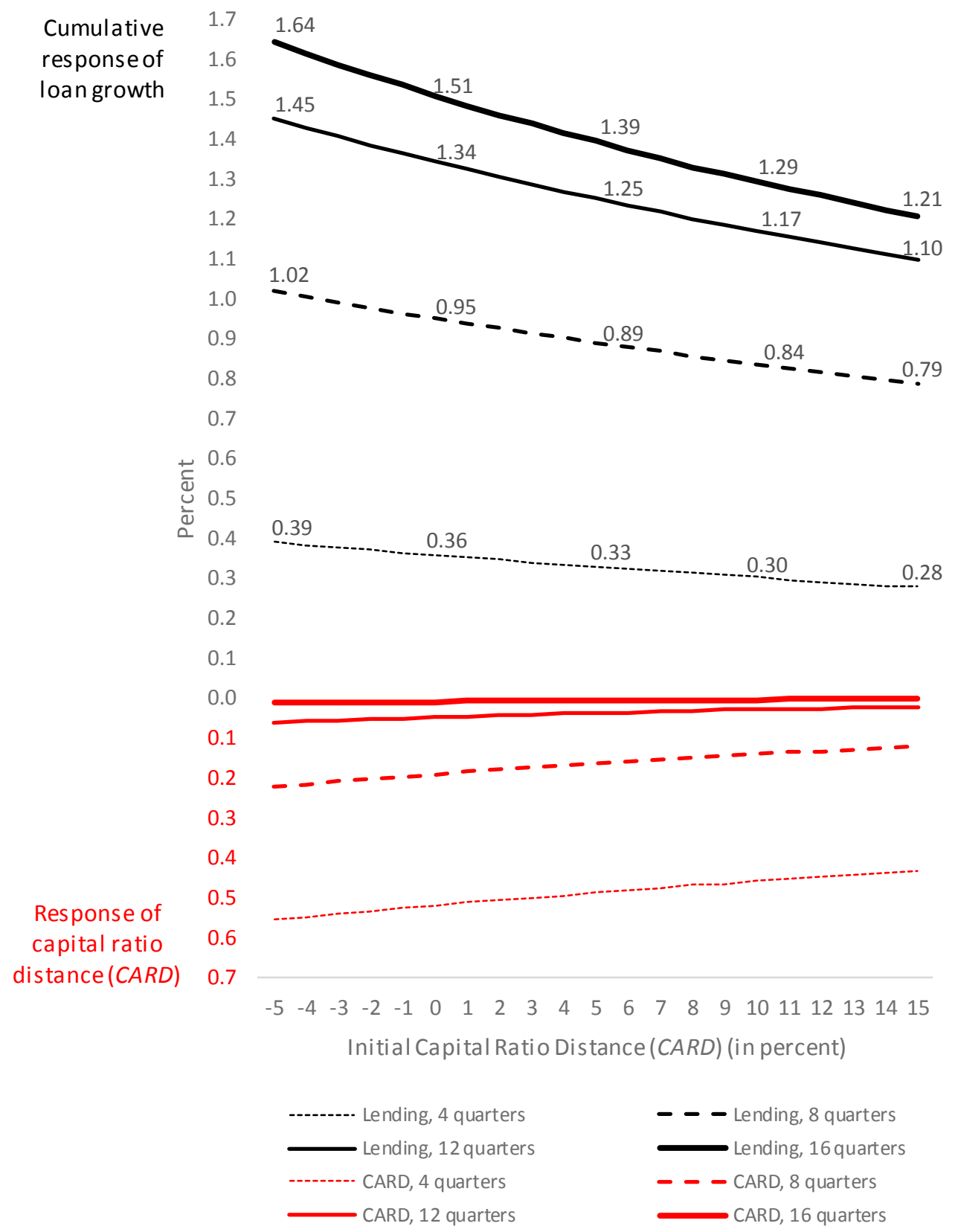

Note. Cumulative responses of loan growth can be interpreted as effects on loan levels. Due to the nonlinearity of the estimated model, responses are history-specific. The responses shown in the Figure were obtained by applying the capital shock in the first quarter of 2005. "Initial $C A R D$ " is defined to include the history up to time $t=0$, and thus, pre-shock $C A R D$ levels at $t=0,-1,-2, \ldots$ differ across (cumulative) impulse responses. 


\section{Figure 2. Pairwise Relationships between Real Loan Growth and Changes in Capital Ratio Distance}
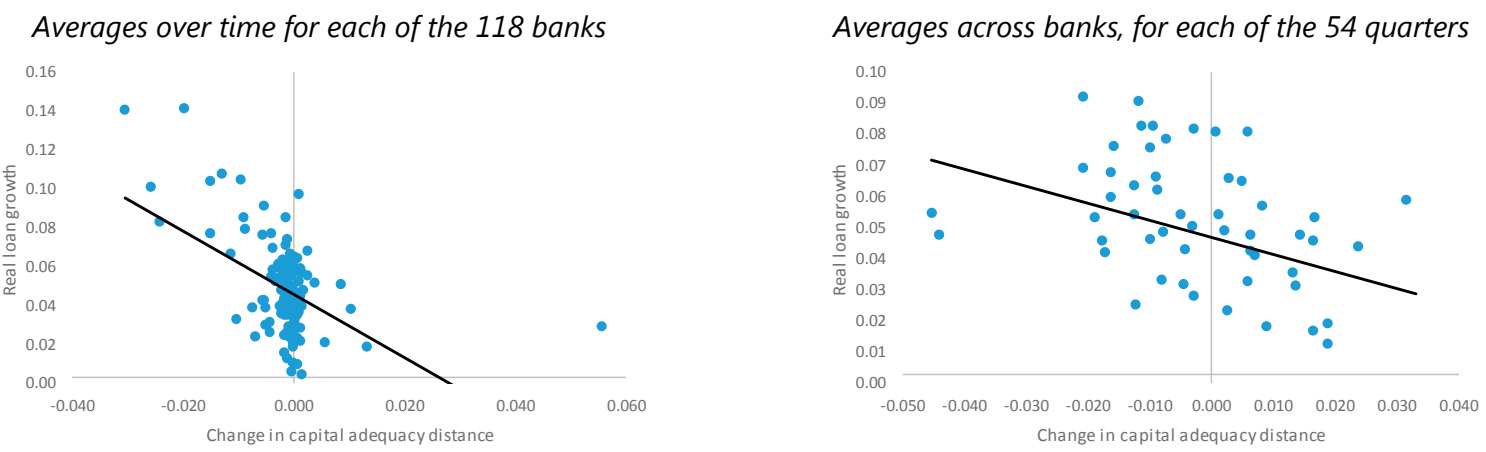

Source: authors' calculations. Note. The Figure shows 118 time-averages for each of the banks operating at end-2015 and averages across banks for each of the 54 quarters from 2001:Q1 to 2015:Q1. The line stems from a simple OLS regression for the corresponding data. 
Figure 3. Impulse Responses of Loan Growth: Shocks to Capital Ratio Distance (Eq.
\[ 8 \text { and Eq. 9) } \]

Median Loan Growth Response

Impulse response of loan growth rate

Cumulative response of loan growth
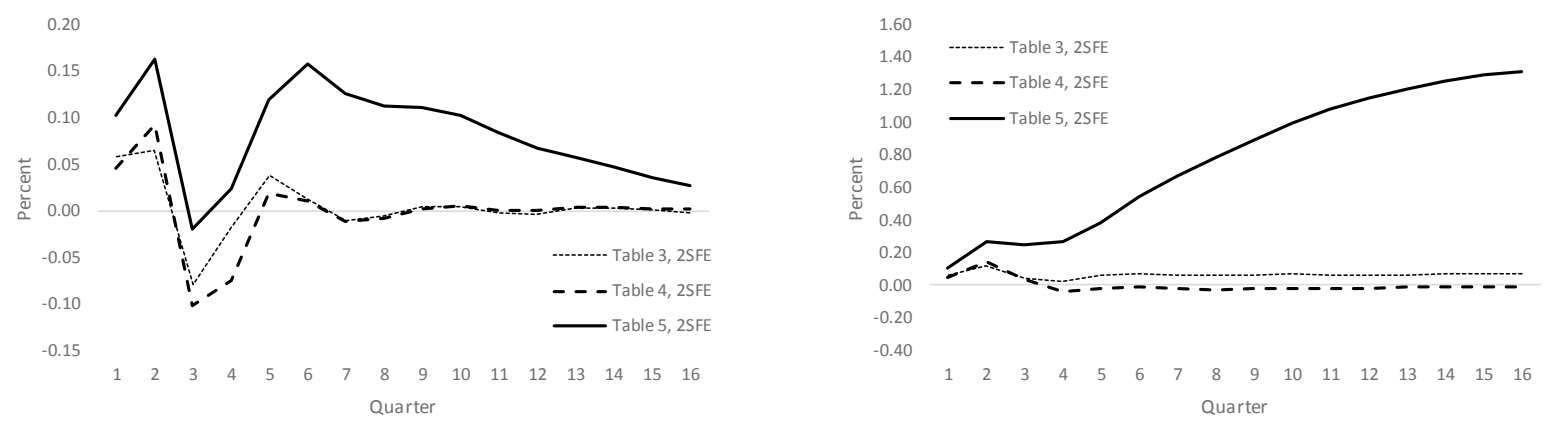

$5^{\text {th }}$ Percentile Loan Growth Response

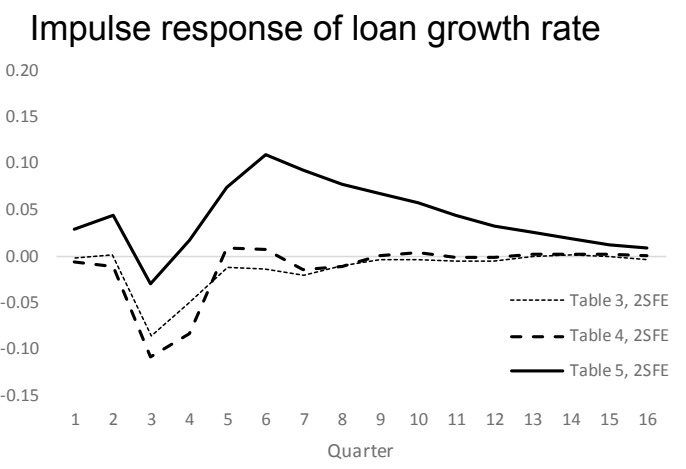

Cumulative response of loan growth

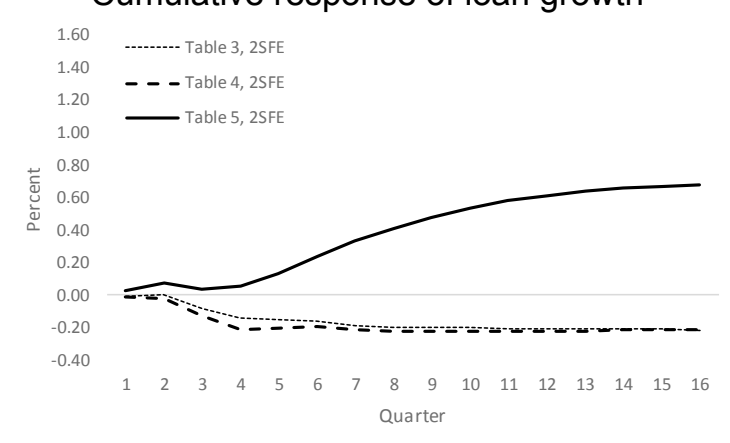

95 ${ }^{\text {th }}$ Percentile Loan Growth Response

Impulse response of loan growth rate

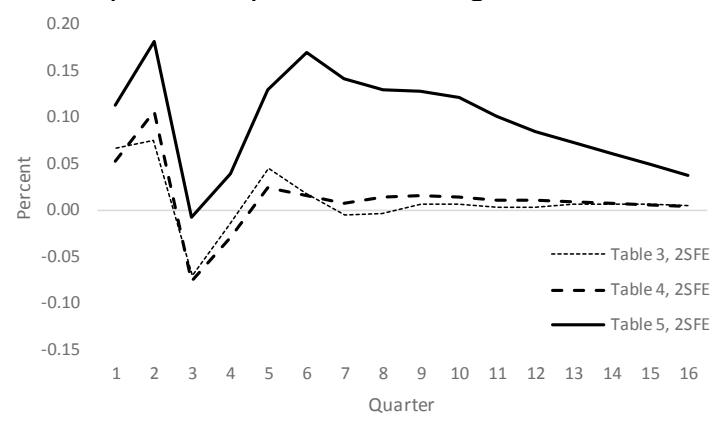

Cumulative response of loan growth

Source: authors' calculations. Note. The Figure shows percentiles of the (quarterly) distributions of bank-specific and history-specific impulse responses for one percentage point shocks to $\triangle C A R D$. The shock is applied in the first quarter of 2005 and lasts one quarter $\left(\omega_{i, t}^{C A R D}=1\right.$ percentage point in the first quarter, when $t=0$, and 0 thereafter). Thus, $C A R D$ increases by 1 percentage point on impact $(t=0)$, and then evolves endogenously. Cumulative responses of loan growth (rates) can be interpreted as effects on loan levels. 
Figure 4. Cumulative Responses of Loan Growth to +/- 1, 5 and 10 Percentage Point Shocks to Capital Ratios, for a Bank with Average Capital Ratio Distance (Eq. 8 and Eq. 9)

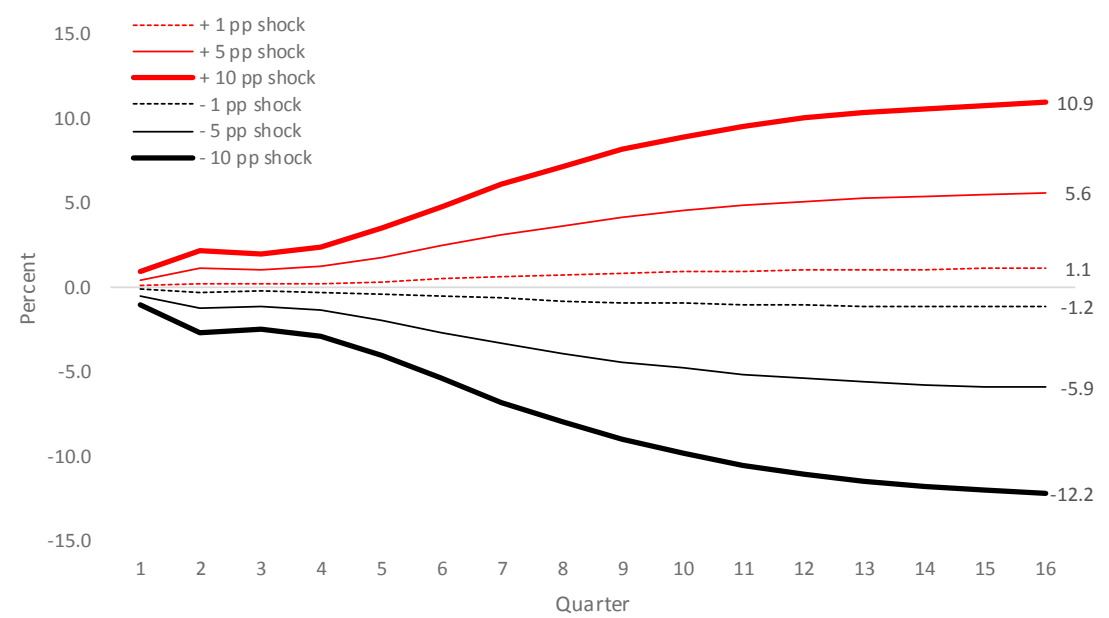

Note. Cumulative responses of loan growth (rates) can be interpreted as effects on loan levels. Due to the nonlinearity of the estimated model, responses are history-specific. The responses shown in the Figure were obtained by applying the capital shock in the first quarter of 2005 to a hypothetical bank with "average" capital ratio distance.

Figure 5. Cumulative Response of Aggregate Loan Growth for +/- 1 Percentage Point Shocks to the Capital Ratio Distance (Eq. 8 and Eq. 9)

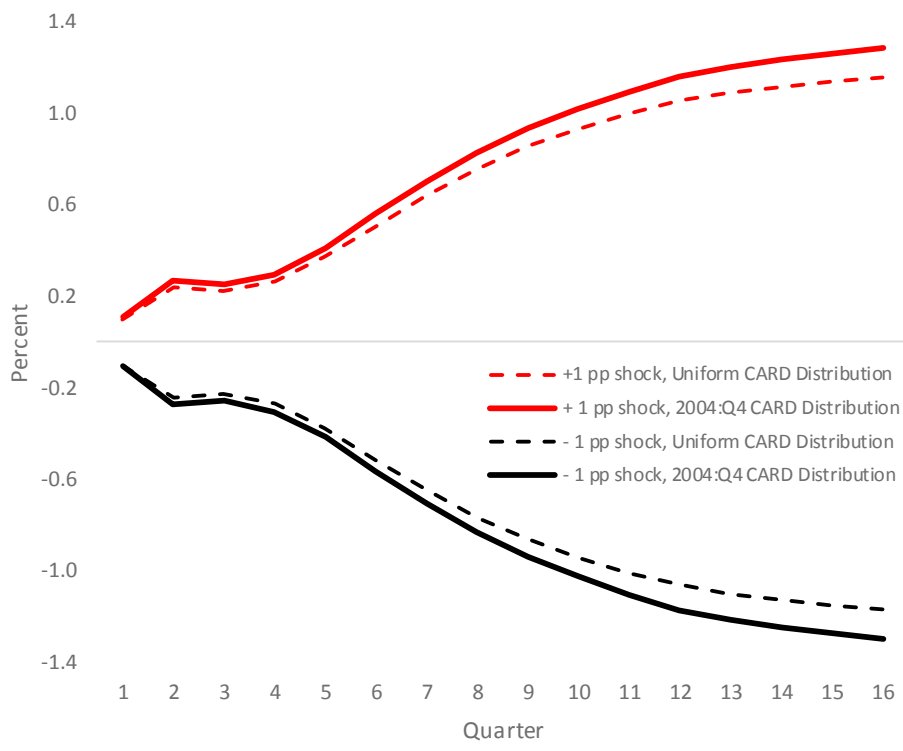

Note. Cumulative responses of loan growth (rates) can be interpreted as effects on loan levels. Due to the nonlinearity of the estimated model, responses are history-specific. The responses shown in the Figure were obtained by applying the capital shock in the first quarter of 2005. 


\section{APPENDIX I. IMPULSE RESPONSES}

The impulse response function for bank $i, I R_{i}($.$) , to a \triangle C A R D$ shock in period $t=0$ can be expressed as the difference between two forecasts:

$$
I R_{i}\left(\Delta l_{i, s}, \mathbf{l}\right)=E\left[\Delta l_{i, s} / \boldsymbol{h}_{\Delta x}^{s-1}(\boldsymbol{\omega}=\mathbf{\imath}), \boldsymbol{h}_{\Delta z}^{s-1}\right]-E\left[\Delta l_{i, s} / \boldsymbol{h}_{\Delta x}^{s-1}(\boldsymbol{\omega}=\mathbf{0}), \boldsymbol{h}_{\Delta z}^{s-1}\right], s=1,2,3 \ldots,
$$

where $\boldsymbol{h}_{\Delta x}^{s-1}(\omega)=\left\{\ldots, \Delta \tilde{\boldsymbol{x}}_{i, 0}, \Delta \boldsymbol{x}_{i, 1}, \ldots, \Delta \boldsymbol{x}_{i, s-1}\right\}$ and $\boldsymbol{h}_{\Delta z}^{s-1}=\left\{\ldots, \Delta \boldsymbol{z}_{i, 0}, \Delta \boldsymbol{z}_{i, 1}, \ldots, \Delta \boldsymbol{z}_{i, s-1}\right\}$ denote the histories of $\Delta \boldsymbol{x}_{i, t}$ and $\Delta \boldsymbol{z}_{i, t}$ up to time $s-1 ; \boldsymbol{\omega}^{\prime}=\left(\boldsymbol{\omega}_{x}^{\prime}, \mathbf{0}^{\prime}\right)$ is defined as

$$
\left(\begin{array}{c}
\Delta \tilde{\boldsymbol{x}}_{i, 0} \\
\Delta \boldsymbol{z}_{i, 0}
\end{array}\right)=\left(\begin{array}{c}
\Delta \boldsymbol{x}_{i, 0} \\
\Delta \boldsymbol{z}_{i, 0}
\end{array}\right)+\left(\begin{array}{c}
\omega_{x} \\
\mathbf{0}
\end{array}\right)
$$

and $\mathbf{\imath}$ denotes the "shock" vector, where the variable $\omega_{i, 0}^{C A R D}$ takes the value 1 and all others are zero, so that the baseline and counterfactual forecasts correspond to expectations of loan growth when $\boldsymbol{\omega}=\mathbf{0}$ and $\boldsymbol{\omega}=\mathbf{1}$, respectively. ${ }^{36,37}$ Impulse responses for $\triangle C A R D_{i, s}$, $s=1,2,3 \ldots$, can be defined and computed in an analogous manner.

For the ARDL model that includes both a linear and a quadratic term for $\triangle C A R D$, explicit derivation of impulse responses for $s=1,2$ can illustrate the fact that impulse responses are "history-specific", "shock-specific", and "asymmetric". To simplify notation, we omit subscript $i$ and the conditioning histories in the expectations operator $E($.$) .$

As of time $t=0, \triangle C A R D_{0}$ and $\Delta l_{0}$ are given as part of the history upon which the forecasts are conditioned. The realization of the capital shock implies $\triangle C A R D_{0}^{\prime}=\triangle C A R D_{0}+\omega_{0}^{C A R D}$; as the minimum capital requirement $\overline{C A R}$ remains unchanged, it follows that $C A R_{0}^{\prime}=C A R_{0}+\omega_{0}^{C A R D}$.

The one-quarter ahead baseline and counterfactual forecasts for loan growth, which are respectively denoted by $E\left(\Delta l_{1}\right)$ and $E\left(\Delta l_{1}^{\prime}\right)$, are given by:

$$
E\left(\Delta l_{1}\right)=\xi+\alpha_{1} \cdot \Delta l_{0}+\alpha_{2} \cdot \Delta l_{-1}+\ldots+\beta_{1} \cdot \Delta C A R D_{0}+\gamma_{1} \cdot\left(\Delta C A R D_{0}\right)^{2}+\beta_{2} \cdot \Delta C A R D_{-1}+\gamma_{2} \cdot\left(\Delta C A R D_{-1}\right)^{2}+\vartheta_{1}
$$

\footnotetext{
${ }^{36}$ When the specification allows for $C A R D$ to have long-run loan growth effects, that is, when it also appears in levels, as in equation (8), the dynamic forecasting model includes an identity tying the level of $C A R D$ to its respective change. Also, in versions of the model that include the quadratic term $\triangle C A R D^{2}$ an identity also ties the level of $C A R D$ to its squared term.

${ }^{37}$ Jordà (2005) proposed using multiple forecasting models (optimized for specific forecast horizons) to compute impulse responses using "local projections." These impulse responses simplify statistical inference and appear more robust to misspecification of the data generating process. But they come at a cost of lost degrees of freedom (equal to the maximum horizon of interest). Here, these would exhaust the degrees of freedom for an individual bank by forecast horizon eight. Moreover, confidence intervals from impulse responses based on local projection have been found to be less reliable those based on standard methods (Kilian and Kim, 2011).
} 
$E\left(\Delta l_{1}^{\prime}\right)=\xi+\alpha_{1} \cdot \Delta l_{0}+\alpha_{2} \cdot \Delta l_{-1}+\ldots+\beta_{1} \cdot \Delta C A R D_{0}^{\prime}+\gamma_{1} \cdot\left(\Delta C A R D_{0}^{\prime}\right)^{2}+\beta_{2} \cdot \Delta C A R D_{-1}+\gamma_{2} \cdot\left(\Delta C A R D_{-1}\right)^{2}+\vartheta_{1}$,

where $\vartheta_{1}$ summarizes additional terms that are cancelled out in the calculation of the impulse response which is given by: $\operatorname{IR}\left(\Delta l_{1}\right)=E\left(\Delta l_{1}^{\prime}-\Delta l_{1}\right)=\left(\beta_{1}+2 \cdot \gamma_{1} \cdot \Delta C A R D_{0}\right) \cdot \omega_{0}^{C A R D}+\gamma_{1} \cdot\left(\omega_{0}^{C A R D}\right)^{2}$.

Note that the one-quarter ahead response of loan growth is quadratic on the size of the shock; thus, the response is shock-specific and asymmetric. This response also depends on the historical information summarized in $\triangle C A R D_{0}$ but not on the history prior to time $t=0$.

The one-quarter ahead impulse response for $\triangle C A R D$ is given by: $\operatorname{IR}\left(\triangle C A R D_{1}\right)=E\left(\triangle C A R D_{1}^{\prime}-\triangle C A R D_{1}\right)=-C A R_{0}^{\prime} \cdot E\left(\Delta l_{1}^{\prime}\right)+C A R_{0} \cdot E\left(\Delta l_{1}\right)$, which after some substitutions can be expressed as a function of the shock, the baseline forecast for loan growth, and the impulse response for loan growth:

$\operatorname{IR}\left(\triangle C A R D_{1}\right)=\omega_{0}^{C A R D} \cdot E\left(\Delta l_{1}\right)-C A R D_{0}^{\prime} \cdot \operatorname{IR}\left(\Delta l_{1}\right)$.

Note that $E\left(\Delta l_{1}\right)$ and thus $\operatorname{IR}\left(\triangle C A R D_{1}\right)$ depend on the whole history of right-hand side variables that enter the loan growth baseline forecast (not just $\triangle C A R D_{0}$ ).

The two-quarter ahead response of loan growth can be written as follows:

$$
\begin{aligned}
\operatorname{IR}\left(\Delta l_{2}\right)=E\left(\Delta l_{2}^{\prime}-\Delta l_{2}\right)= & \alpha_{1} \cdot \operatorname{IR}\left(\Delta l_{1}\right)+\beta_{1} \cdot \operatorname{IR}\left(\Delta C A R D_{1}\right)+\beta_{2} \cdot \omega_{0}^{C A R D} \\
& +\gamma_{1} \cdot\left\{\operatorname{IR}\left(\Delta C A R D_{1}\right)^{2}+2 \cdot \Delta C A R D_{1} \cdot \operatorname{IR}\left(\Delta C A R D_{1}\right)\right\} \\
& +\gamma_{2} \cdot\left\{\left(\omega_{0}^{C A R D}\right)^{2}+2 \cdot \Delta C A R D_{0} \cdot \omega_{0}^{C A R D}\right\} .
\end{aligned}
$$

Note that the response depends on $\triangle C A R D_{1}=\Xi^{\mathrm{AVG}}-C A R_{0} \cdot \Delta l_{1}$, and thus, changes in the value of $\Xi^{\mathrm{AVG}}$ affect the impulse responses for $s=2,3, \ldots$. However, as discussed in the main text (footnote 30 ), $\Xi^{\mathrm{AVG}}$ only exerts second order (negligible) effects in the numerical impulse responses - results are robust to sizable changes in the value of this parameter.

\section{APPENDIX II. DATA SOURCES AND DEFINITIONS}

Liquid assets to total assets ratio. Liquid assets comprise cash, bonds (SBI, SDBI, and SBN), reverse repos, term deposits, and balances and placements with the central bank (after deducting mandatory reserves).

Non-performing loan ratio. In Indonesia, the classification of loans and the provisioning requirements (indicated in parenthesis) are as follows: pass ( 1 percent), special mention (5 percent), substandard (15 percent), doubtful (50 percent), and loss (100 percent); the last three categories correspond to "non-performing" loans.

Tobin's $Q$. Measures of Tobin's $\mathrm{Q}$ for the corporate loan exposures of individual banks were constructed by combining historical series of $Q$ measures by sector of economic activity and 
supervisory data about the sectoral distribution of each bank's loan portfolio. The exact definition and data surce (in parenthesis) are as follows: Tobin's $\mathrm{Q}=$ Total assets (Worldscope item 02999) plus market value of equity (Worldscope item 08001) minus book value of equity (Worldscope item 03501) divided by total assets (Worldscope item 02999).

\begin{tabular}{|c|c|c|c|}
\hline \multicolumn{4}{|c|}{$\begin{array}{c}\text { Appendix II,Table 1. Sectoral Mapping for Calculation of } \\
\text { Tobin's Q of Bank-specific Corporate Borrowers }\end{array}$} \\
\hline \multirow{2}{*}{$\begin{array}{l}\text { BI Loan Classification by } \\
\text { Economic Sector }\end{array}$} & \multicolumn{3}{|c|}{ Sectoral Classification In Datastream (Tobin's Q) } \\
\hline & Sector & Share by Assets & Number of Companies \\
\hline Agriculture, Livestock, Forestry \& Fishery & Consumer Goods & 10 & 96 \\
\hline Mining and Quarrying & Basic Materials & 10 & 79 \\
\hline Manufacturing Industry & Industrials & 5 & 88 \\
\hline Electricity, Gas and Water Supply & Utilities & 1 & 3 \\
\hline Construction & Industrials & 5 & 88 \\
\hline Trade, Hotel, and Restaurant & Consumer Services & 3 & 65 \\
\hline Transport and Communication & Telecommunications (0.47) and Industrials (0.53) & 5 (Telecommunications) +5 (Industrials) & 9 (Telecommunications) +88 (Industrials) \\
\hline Financial, Ownership \& Business Services & Financials & 63 & 143 \\
\hline Services & Consumer Services $(0.87)$ and Health Care $(0.13)$ & 3 (Consumer Servces) +1 (Health Care) & 65 (Consumer Servces) +15 (Health Care) \\
\hline Other & Average of all other sectors & $\ldots$ & $\ldots$ \\
\hline
\end{tabular}

Source: Worldscope and and authors' calculations.

\section{APPENDiX III. RobUSTness ANALYSIS}

Appendix III-Table 1 shows regression estimates corresponding to equation 8 (2SFE) where either inflation is included as a macroeconomic determinant of long-run loan growth or a single instrument (house price inflation or Tobin's Q) is used. The results of the former fail the Wu-Hausman specification test at the 10 percent marginal significance level, while the results of the latter are qualitatively unchanged from those discussed in the main text. 


\section{Appendix III, Table 1. Robustness Analysis: Regression Results}

\begin{tabular}{|c|c|c|c|c|c|c|c|c|c|c|}
\hline \multirow[b]{3}{*}{ Dependent variable: Real loan growth: $\Delta l_{i, t}$} & \multirow[b]{3}{*}{$\begin{array}{c}\text { Lags } \\
\text { included: } \\
S\end{array}$} & \multicolumn{3}{|c|}{$\begin{array}{c}\text { Inflation as Long-Run Growth Determinant } \\
T_{\text {wo-stage fixed-effects estimation }}\end{array}$} & \multicolumn{3}{|c|}{$\begin{array}{l}\text { Single Instrument: House Price Inflation } \\
\text { Two-stage fixed-effects estimation }\end{array}$} & \multicolumn{3}{|c|}{$\begin{array}{c}\text { Single Instrument: Tobin's } Q \\
\text { Two-stage fixed-effects estimation }\end{array}$} \\
\hline & & \multirow{2}{*}{$\begin{array}{c}\text { Sum of } \\
\text { coefficient } \\
\text { estimates }\end{array}$} & \multicolumn{2}{|c|}{ Hypothesis tests } & \multirow{2}{*}{$\begin{array}{c}\text { Sum of } \\
\text { coefficient } \\
\text { estimates }\end{array}$} & \multicolumn{2}{|c|}{ Hypothesis tests } & \multirow{2}{*}{$\begin{array}{l}\text { Sum of } \\
\text { coefficient } \\
\text { estimates }\end{array}$} & \multicolumn{2}{|c|}{ Hypothesis tests } \\
\hline & & & $\begin{array}{c}\text { Sum equals zero } \\
(p \text {-value })\end{array}$ & $\begin{array}{c}\text { Exclusion test } \\
\text { (p-value) }\end{array}$ & & $\begin{array}{c}\text { Sum equals zero } \\
\text { (p-value) }\end{array}$ & $\begin{array}{c}\text { Exclusion test } \\
\text { (p-value) }\end{array}$ & & $\begin{array}{l}\text { Sum equals zero } \\
\text { (p-value) }\end{array}$ & $\begin{array}{c}\text { Exclusion test } \\
\text { (p-value) }\end{array}$ \\
\hline \multicolumn{11}{|l|}{ Short-run dynamic effects } \\
\hline \multicolumn{11}{|l|}{ Lagged dependent variable } \\
\hline Real loan growth: $\Delta l_{i, t-s}$ & 1 to 4 & 0.307 & $11.3(0.00)$ & $48.8(0.00)$ & 0.320 & $12.4(0.00)$ & $57.7(0.00)$ & 0.314 & $11.8(0.00)$ & $54.6(0.00)$ \\
\hline \multicolumn{11}{|l|}{ Change in nominal lending rate } \\
\hline Change in nominal lending rate: $\Delta i_{i, t-s}^{I}$ & 0 to 4 & 4.228 & $1.6(0.11)$ & $5.9(0.00)$ & 0.088 & $0.0(0.98)$ & $6.3(0.00)$ & 1.974 & $0.6(0.54)$ & $6.0(0.00)$ \\
\hline \multicolumn{11}{|l|}{ Change in bank specific fundamentals } \\
\hline Change in non-performing loan ratio: $\triangle N P L R_{i, t-s}$ & 1 to 5 & -0.532 & $-2.7(0.01)$ & $5.3(0.00)$ & -0.638 & $-3.1(0.00)$ & $6.3(0.00)$ & -0.551 & $-2.6(0.01)$ & $5.6(0.00)$ \\
\hline Change in liquid assets ratio: $\triangle L A T A_{i, t-s}$ & 1 to 5 & 0.010 & $0.4(0.72)$ & $0.1(0.98)$ & -0.013 & $-0.5(0.63)$ & $0.2(0.97)$ & -0.004 & $-0.2(0.88)$ & $0.1(0.99)$ \\
\hline Change in capital adequacy distance: $\triangle C A R D_{i, t-s}$ & 1 to 5 & -0.469 & $-3.5(0.00)$ & $5.1(0.00)$ & -0.424 & $-3.4(0.00)$ & $4.8(0.00)$ & -0.439 & $-3.4(0.00)$ & $4.8(0.00)$ \\
\hline Change in capital adequacy distance squared: $\triangle C A R D_{i, t-s}^{2}$ & 1 to 5 & 0.029 & $0.3(0.74)$ & $1.7(0.13)$ & 0.029 & $0.4(0.72)$ & $1.1(0.33)$ & 0.026 & $0.3(0.75)$ & $1.2(0.29)$ \\
\hline \multicolumn{11}{|l|}{ Change in macroeconomic variables (common effects) } \\
\hline Change in policy rate: $\Delta t_{t-s}^{d}$ & 0 to 4 & -2.106 & $-1.9(0.05)$ & $2.2(0.05)$ & -0.812 & $-0.6(0.54)$ & $1.8(0.11)$ & -1.595 & $-1.1(0.25)$ & $1.9(0.08)$ \\
\hline Change in real GDP growth: $\triangle R G D P G_{t-s}$ & 0 to 4 & -3.790 & $-1.1(0.29)$ & $12.6(0.00)$ & -6.361 & $-2.0(0.05)$ & $14.5(0.00)$ & -5.788 & $-1.7(0.08)$ & $14.1(0.00)$ \\
\hline Change in inflation rate: $\Delta I N F_{t-s}$ & 0 to 4 & 0.039 & $0.0(0.98)$ & $1.1(0.37)$ & -2.685 & $-3.2(0.00)$ & $14.6(0.00)$ & -2.785 & $-3.2(0.00)$ & $14.0(0.00)$ \\
\hline \multicolumn{11}{|l|}{ Long-run effects } \\
\hline \multicolumn{11}{|l|}{ Bank-specific } \\
\hline Non-performing loan ratio: $N P L R_{i, t-1}$ & 1 & -0.071 & $-1.9(0.05)$ & $3.7(0.05)$ & -0.085 & $-2.5(0.01)$ & $6.0(0.01)$ & -0.090 & $-2.6(0.01)$ & $6.5(0.01)$ \\
\hline Liquid assets ratio: $L A T A_{i, t-1}$ & 1 & 0.025 & $3.4(0.00)$ & $11.5(0.00)$ & 0.026 & $3.8(0.00)$ & $14.7(0.00)$ & 0.026 & $3.7(0.00)$ & $13.8(0.00)$ \\
\hline Capital adequacy distance: $C A R D_{i, t-1}$ & 1 & 0.190 & $6.4(0.00)$ & $40.7(0.00)$ & 0.194 & $7.0(0.00)$ & $49.3(0.00)$ & 0.191 & $6.7(0.00)$ & $45.3(0.00)$ \\
\hline Capital adequacy distance squared: $C A R D_{i, t-1}^{2}$ & 1 & -0.064 & $-3.0(0.00)$ & $9.3(0.00)$ & -0.069 & $-3.5(0.00)$ & $12.4(0.00)$ & -0.066 & $-3.3(0.00)$ & $10.9(0.00)$ \\
\hline \multicolumn{11}{|l|}{ Macroeconomic (common) } \\
\hline Real GDP growth: $R G D P G_{t}$ & 0 & 5.937 & $4.4(0.00)$ & $19.5(0.00)$ & 5.334 & $3.6(0.00)$ & $13.1(0.00)$ & 6.007 & $3.9(0.00)$ & $10.9(0.00)$ \\
\hline Inflation: $I N F_{t}$ & 0 & -0.971 & $-2.6(0.01)$ & $7.0(0.01)$ & & & & & & \\
\hline Adjusted $R^{2}$ & & 0.167 & & & 0.166 & & & 0.166 & & \\
\hline Standard error of the regression & & 0.120 & & & 0.110 & & & 0.113 & & \\
\hline Number of observations & & 5786 & & & 5786 & & & 5786 & & \\
\hline \multicolumn{11}{|l|}{ Memo items } \\
\hline \multicolumn{11}{|l|}{ Lagragian Multiplier test for serial correlation } \\
\hline Order 1 & & 0.14 & $(0.83)$ & & 0.50 & (0.62) & & 0.32 & (0.75) & \\
\hline Order 2 & & 0.09 & $(0.90)$ & & 0.21 & $(0.83)$ & & 0.19 & $(0.85)$ & \\
\hline Order 3 & & -0.55 & $(0.60)$ & & -0.44 & $(0.66)$ & & -0.52 & $(0.61)$ & \\
\hline Order 4 & & -1.87 & $(0.06)$ & & -2.02 & $(0.04)$ & & -1.94 & $(0.05)$ & \\
\hline F-test for first stage regression & & 13.55 & $(0.00)$ & & 13.77 & $(0.00)$ & & 13.77 & $(0.00)$ & \\
\hline F-test for first stage outside instruments & & 3.64 & $(0.00)$ & & 3.90 & $(0.00)$ & & 9.39 & $(0.00)$ & \\
\hline Wu-Hausman exogeneity test & & 4.85 & $(0.03)$ & & 1.93 & $(0.17)$ & & 1.93 & $(0.17)$ & \\
\hline Hansen over-identification test & & 0.33 & $(1.00)$ & & 0.33 & $(1.00)$ & & 0.32 & $(1.00)$ & \\
\hline Pesaran cross-sectional dependence test & & 6.44 & $(0.00)$ & & 1.55 & (0.12) & & 1.66 & $(0.10)$ & \\
\hline
\end{tabular}

Source: Bank of Indonesia and authors' calculations. Note. As indicated, pooled panel estimates correspond to two-stage fixed effects estimators using a single (outside) instrument, namely Tobin's Q or housing price inflation. All estimates are based on an unbalanced panel of quarterly data from 2001:Q1 to 2015:Q1 for 118 banks operating in Indonesia at end-2015. The estimated ARDL models contain the contemporaneous and lagged observations for the regressors as indicated; with the exception of the long-run effect of regressors, coefficient estimates have been summarized by their sum. In this regard, two null hypothesis test are reported for each regressor: (1) the sum of coefficients equals zero, and (2) every coefficient is equals zero. The table also reports a series of specification tests for all regressions: (1) absence of serial correlation of orders 1 to 4; and (2) lack of cross-sectional dependence as well as (4) all coefficients in the "first-stage" regression are zero; (5) all coefficients of the outside instruments are zero; and (6) instruments are valid (orthogonal to the residuals). In all cases, the null hypothesis is rejected at the 5 (10) percent significance level whenever the p-value (marginal significance level) is less than $5(10)$ percent. 


\section{APPENDIX IV. EQUATION (9) ESTIMATION AND ROBUSTNESS OF IMPULSE RESPONSES}

Conditional on the "drag" coefficient of -1 , the estimation of equation (9) is limited to $\Xi_{i}^{\text {AVG }}$ for $i=1,2, \ldots, 118$. These estimates correspond to the bank-specific intercepts in a panel regression ("fixed-effects") and are shown in Appendix IV-Table 1. The log-likelihood test contrasting the restricted model (OLS) with the unrestricted model (fixed-effects) does not reject the null hypothesis $\Xi_{i}^{\mathrm{AVG}}=\Xi^{\mathrm{AVG}}$ at standard significance levels.

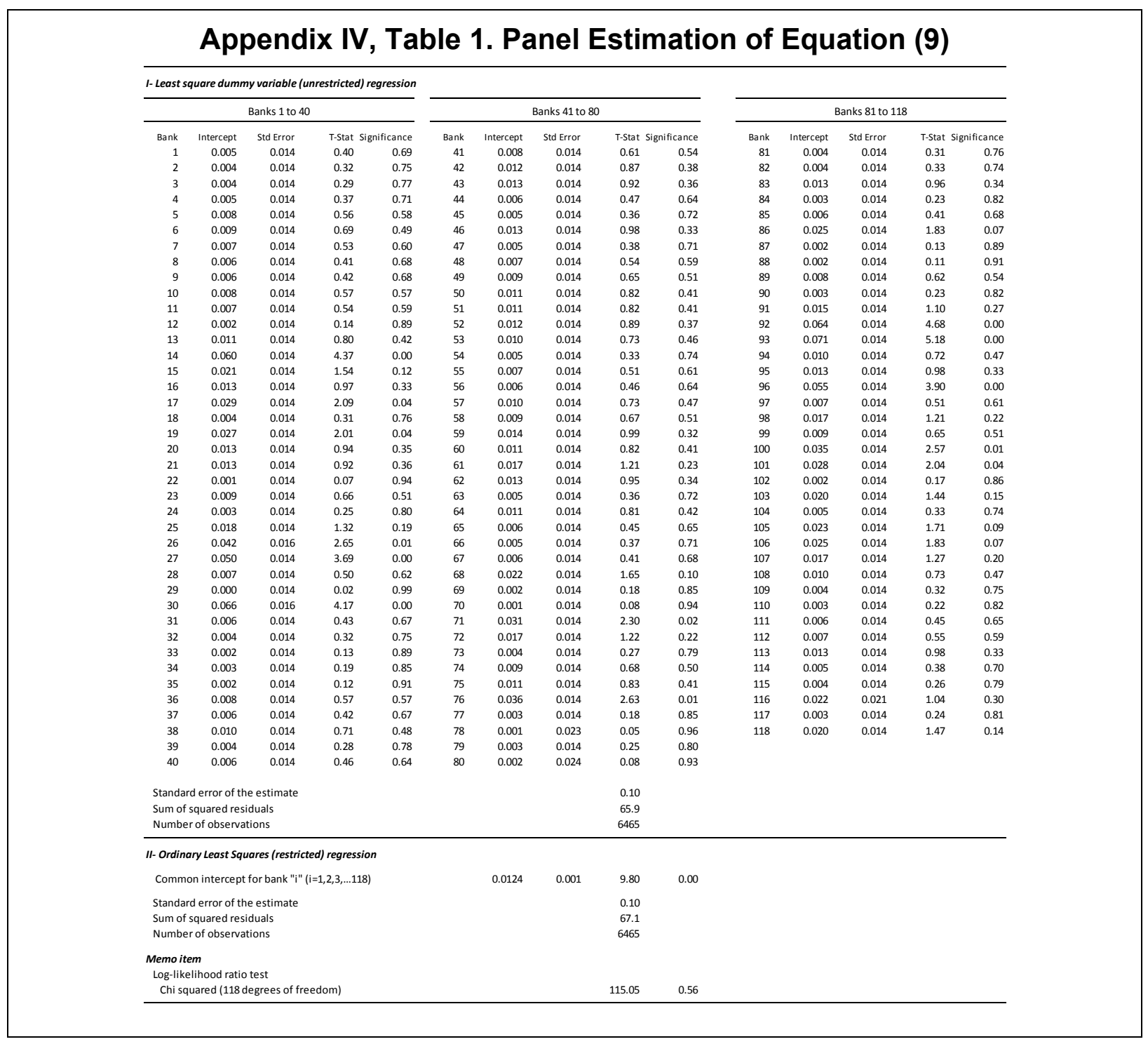

Source: Bank Indonesia and authors' calculations. Note. All estimates are based on an unbalanced panel of quarterly data from 2001:Q1 to 2015:Q1 for 118 operating in Indonesia at end-2015. The individual "fixed-effects" intercepts correspond to the least square dummy variable (LSDV) estimates. The common intercept corresponds to the ordinary least square (OLS) estimates of a common (panel-wide) intercept. All estimates have been obtained for a "drag" coefficient of -1 in accordance with equation (9). The log-likelihood test contrasts the (sum of squared residuals of the) LSDV and OLS. 


\section{References}

Adrian, Tobias, and Hyun Song Shin, 2010, "Liquidity and Leverage," Journal of Financial Intermediation, Vol. 19, Issue 3, pp. 418-37.

Anderson, T. W. and C. Hsiao, "Estimation of Dynamic Models with Error Components, Journal of the American Statistical Association, Vol. 76, pp. 598-606.

Arellano, M, and S. Bond, Some Tests of Specification for Panel Data: Monte Carlo Evidence and an Application to Employment Equations, Review of Economic Studies, Vol. 58, pp 277-97.

Attanasio. Orazio P. and Guglielmo Weber, 2010, "Consumption and Saving: Models of Intertemporal Allocation and Their Implications for Public Policy," Journal of Economic Literature, September, Vol. 48, issue 3, pp. 693-751.

Assenmacher-Wesche, Katrin and M. Hashem Pesaran, 2008, "A VECX Model of the Swiss Economy,” CESINFO Working Paper \#2281, Category 10: Empirical and Theoretical Methods, April.

Berrospide, Jose M., and Rochelle M. Edge, 2010, "The Effects of Bank Capital on Lending: What do We Know, and What does It Mean?," International Journal of Central Banking, December, pp. 5-63.

Bocola, Luigi, 2016, "The Pass-Through of Sovereign Risk," Journal of Political Economy, Vol. 124(4), pp. 879-926.

Bond, Steve, Asli Leblebicioglu, and Fabio Schiantarelli, 2010, "Capital Accumulation and Growth: A New Look at the Empirival Evidence," Journal of Applied Econometrics, Vol. 25, No. 7, November-December, pp.1073-1099.

Breshnan, Timothy F., 1989, "Empirical Studies of Industries with Market Power,” Handbook of Industrial Organization, Edited by Schmalensee R. and R.D. Willig, Volume II, Chapter 17, pp. 1011-1057.

Brunnermeier Markus K., Luis Garicano, Philip R. Lane, Marco Pagano, Ricardo Reis, Tan Santos, David Thesmar, Stijn Van Nieuwerburgh, and Dimitri Vayanos, 2016, "The Sovereign-Bank Diabolic Loop and ESBies," American Economic Review: Papers and Proceedings, Vol. 106(5), pp. 508-12.

Brunnermeier Markus K., and Yuliy Sannikov, 2016, “The I Theory of Money,” NBER Working Paper No. 22533.

Chirinko, Robert S., 1993, "Business Fixed Investment Spending: Modeling Strategies, Empirical Results, and Policy Implications," Journal of Economic Literature, December, Vol. XXXI, pp. 1875-1911. 
Choi, Dong Beom, 2014, "Heterogeneity and Stability: Bolster the Strong, Not the Weak," Review of Financial Studies, Vol 27, No. 6, pp. 1830-1867.

Fahri, Emannuel and Jean Tirole, 2016. "Deadly Embrace: Sovereign and Financial Balance Sheet Doom Loops,” NBER Working Paper No. 21843.

Fazzari, Steven M., Glenn R. Hubbard, and Bruce C. Petersen, 1988, "Financing Constraints and Corporate Investment," Brrokings Papers on Economic Activity, No. 1, pp. 141206.

Gambacorta, Leonardo and Paolo E. Mistrulli, 2004, "Does Bank Capital Affect Lending Behavior?” Journal of Financial Intermediation, Vol 13, pp. 436-457.

Gambacorta, Leonardo and Hyun Song Shin, 2016, "Why Bank Capital Matters for Monetary Policy," Journal of Financial Intermediation, pp. 1-13.

Gorton, Gary, and Andrew Winton, 2003, "Financial Intermediation," Handbook of the Economics of Finance, Chapter 8, Vol. 1, part A, pp. 431-552.

Hanson, Samuel G., Anil K. Kashyap, and Jeremy C. Stein, 2011, “A Macroprudential Approach to Financial Regulation," Journal of Economic Perspectives, Vol. 25, No. 1, pp. 3-28.

Hamilton, James D., 1994, Time Series Analysis, Princeton University Press.

Hubbard, Glenn R., 1998, “Capital-Market Imperfections and Investment," Journal of Economic Literature, Vol. XXXVI, March, pp. 193-225.

Jordà, Òscar, 2005, "Estimation and Inference of Impulse Responses by Local Projections," American Economic Review, March, Vol 95, No 1, pp. 161-182.

Jorgenson, Dale W., 1971, "Econometric Studies of Investment Behavior: A Survey," Journal of Economic Literature, December, 9(4), pp. 111-47.

Judson, R., and A. Owen, 1999, "Estimating Dynamic Panel Data Models: A Practical Guide for Macroeconomists," Economics Letters, Vol. 65, pp. 9-15.

Kaminsky, Graciela L. and Carmen M. Reinhart, 1999, "The Twin Crises: The Causes of Banking and Balance of Payment Problems," American Economic Review, Vol 89, No. 3, pp. 473-500.

Kilian, Lutz and Yun Jung Kim, 2011, "How Reliable Are Local Projection Estimators of Impulse Respones?" Review of Economics and Statistics, November, Vol. 93, No. 4, pp. 1460-66 
Koop, Gary, M. Hashem Pesaran, and Simon M. Potter, 1996, "Impulse Response Analysis in Nonlinear Multivariate Models, Journal of Econometrics, September, Vol. 74, pp. $119-47$.

Laeven Luc and Fabián Valencia, 2013a, "The Real Effects of Financial Sector Interventions during Crises," Journal of Money, Credit, and Banking, Vol. 45, No. 1, pp. 147-177.

Laeven Luc and Fabián Valencia, 2013b, "Systemic Banking Crises Database," IMF Economic Review, June, Vol. 61, Issue 2, pp. 225-270.

Li, D, 2002, "Is the AK Model Still Alive? The Long-run Relation between Growth and Investment Re-examined," Canadian Journal of Economics, Vol. 35, pp. 93-113.

Lusardi, Annamaria, and Olivia S. Mitchell, 2007, "Baby Boomer Retirement Security: The Roles of Planning, Financial Literacy, and Housing Wealth," Journal of Monetary Economics, 54(1): 205-24.

Madsen, 2002, "The Causality between Investment and Economic Growth," Economic Letters, Vol. 74, pp. 157-63.

Meh, Cesaire A., and Kevin Moran, 2010, "The Role of Bank Capital in the Propagation of Shocks," Journal of Economic Dynamics and Control, Vol. 34, pp. 555-576.

Nickell, Stephan, 1981, "Biases in Dynamic Models with Fixed Effects," Econometrica, Vol. 49, pp. 1417-1426.

Ong, Rachel, Sharon Parkinson, Beverly A. Searle, Susan J. Smith, and Gavin A. Wood, 2013, "Channels from Housing Wealth to Consumption," Housing Studies, pp. 1-25.

Peek, Joe and Eric S. Rosengren, 2015, "The Role of Banks in the Transmission of Monetary Policy," Oxford Handbooks Online, pp. 1-15.

Pesaran, Hashem M., 2004, "General Diagnostic Tests for Cross-section Dependence in Panels,” CESifo Working Paper No. 1229.

Pesaran, Hashem M., 2006, Estimation and Inference in Large Heterogenous Panels with Multifactor Error Structure,” Econometrica, Vol. 74, pp. 967-1012.

Pesaran, Hashem M., 2015. Time Series and Panel Data Econometrics. Oxford University Press.

Pesaran, Hashem M., and Ron Smith, 1995, "Estimating Long-run Relationships from Dynamic Heterogeneous Panels," Journal of Econometrics, Vol. 68, pp. 79-113.

Pesaran, Hashem M., and T. Yamataga, 2008, "Testing Slope Homogeneity in Large Panels," Journal of Econometrics, Vol. 142, pp. 50-93. 
Reiss, Peter C. and Frank A. Wolak, 2007, "Structural Econometric Modeling: Rationales and Examples from Industrial Organization," Handbook of Econometrics, Volume 6A, Chapter 64, pp. 4278-4415.

Schneider Martin and Aaron Tornell, 2004, "Balance Sheet Effects, Bailout Guarantees and Financial Crises," Review of Economic Studies, Vol 71, pp. 883-913. 